\title{
miR-ID: A novel, circularization-based platform for detection of microRNAs
}

\author{
PAVAN KUMAR, ${ }^{1}$ BRIAN H. JOHNSTON, ${ }^{1,2}$ and SERGEI A. KAZAKOV ${ }^{\mathbf{1}}$ \\ ${ }^{1}$ Somagenics, Inc., Santa Cruz, California 95060, USA \\ ${ }^{2}$ Department of Pediatrics, Stanford University School of Medicine, Stanford, California 94305, USA
}

\begin{abstract}
MicroRNAs (miRNAs) are important regulators of gene expression and have great potential as biomarkers, prognostic indicators, and therapeutic targets. Determining the expression patterns of these molecules is essential for elucidating their biogenesis, regulation, relation to disease, and response to therapy. Although PCR-based assays are commonly used for expression profiling of miRNAs, the small size, sequence heterogeneity, and (in some cases) end modifications of miRNAs constrain the performance of existing PCR methods. Here we introduce miR-ID, a novel method that avoids these constraints while providing superior sensitivity and sequence specificity at a lower cost. It also has the unique ability to differentiate unmodified small RNAs from those carrying 2'-OMe groups at their 3 '-ends while detecting both forms. miR-ID is comprised of the following steps: (1) circularization of the miRNA by a ligase; (2) reverse transcription of the circularized miRNA (RTC), producing tandem repeats of a DNA sequence complementary to the miRNA; and (3) qPCR amplification of segments of this multimeric cDNA using 5' -overlapping primers and a nonspecific dye such as SYBR Green. No chemically modified probes (e.g., TaqMan) or primers (e.g., LNA) are required. The circular RNA and multimeric cDNA templates provide unmatched flexibility in the positioning of primers, which may include straddling the boundaries between these repetitive miRNA sequences. miR-ID is based on new findings that are themselves of general interest, including reverse transcription of small RNA circles and the use of $5^{\prime}$-overlapping primers for detection of repetitive sequences by qPCR.
\end{abstract}

Keywords: microRNA; RNA circularization; RCA; RT-PCR; 5'-overlapping primers; 2'-OMe

\section{INTRODUCTION}

MicroRNAs (miRNAs) are an important class of small noncoding RNAs with diverse regulatory functions. Among the processes regulated by miRNAs are embryonic development, cell growth and proliferation, tissue differentiation, the cell cycle, and apoptosis (Bushati and Cohen 2007). Altered expression and modification of individual miRNAs have been associated with certain cancers and other disorders (Zhang and Farwell 2008). These associations suggest that miRNAs have potential as diagnostic biomarkers, prognostic indicators, and therapeutic targets. Expression profiling of miRNAs is essential for elucidating their mechanism of regulation, relation to disease, and response to therapy. Due to their good sensitivity, sequence

Reprint requests to: Sergei A. Kazakov, Somagenics, Inc., 2161 Delaware Ave., Suite E, Santa Cruz, CA 95060, USA; e-mail: skazakov@ somagenics.com; fax: (831) 420-0685.

Article published online ahead of print. Article and publication date are at http://www.rnajournal.org/cgi/doi/10.1261/rna.2490111. specificity, and dynamic range, RT-PCR methods are frequently used for expression profiling of miRNAs and for validating results obtained by other methods such as microarray and Northern blot assays (Aravin and Tuschl 2005; Baker 2010). However, the short length of miRNAs - mostly 21-22 nt, about the size of a standard PCR primer-imposes restrictions because at least two non-overlapping primers are required for exponential amplification (Schmittgen et al. 2004).

Two general strategies have been implemented to overcome this restriction. One strategy involves extension of the miRNA, usually by polyadenylation (Shi and Chiang 2005; Fu et al. 2006; Ro et al. 2006; Reichenstein et al. 2010). Since all RNA molecules with common 3 '-ends become polyadenylated in this procedure, it cannot reliably distinguish between pre-miRNAs and mature miRNAs (Benes and Castoldi 2010), and only the latter are thought to be the proximal effectors of silencing (O'Hara et al. 2009). Another limitation of polyadenylation-based assays is their inability to detect small RNAs carrying a $2^{\prime}$-oxymethyl modification at their $3^{\prime}$-ends $\left(2^{\prime}\right.$-OMe RNAs; e.g., plant miRNAs and 
animal piRNAs) because this modification blocks polyadenylation (Ebhardt et al. 2005; Yang et al. 2006).

The second strategy for assaying miRNAs by RT-PCR uses primers having only a short overlap with the miRNA sequences at their termini (Chen et al. 2005; Raymond et al. 2005; Sharbati-Tehrani et al. 2008; Wang 2009; Yang et al. 2009). Despite their popularity, such primers may compromise both the efficiency and accuracy of RT-PCR due to significant differences in GC content between the $5^{\prime}$ and $3^{\prime}$ halves of individual miRNAs as well as among different miRNAs (Raymond et al. 2005; Sharbati-Tehrani et al. 2008; Baker 2010; Benes and Castoldi 2010; Griffiths-Jones 2010). Moreover, options for optimizing these primer sequences are very limited. Among the latter methods, the TaqMan microRNA assay, which uses stem-loop RT primers together with miRNA-specific TaqMan probes, is often considered as the "gold standard" for microRNA detection (Chen et al. 2005; ABI 2010). Modified versions of the TaqMan assay that use an alternative primer design and target-specific probes have also been described recently (Lao et al. 2006; Yang et al. 2009; Varkonyi-Gasic and Hellens 2010; Wan et al. 2010). Other available RT-qPCR miRNA assays use a single nonspecific dye such as SYBR Green rather than miRNA-specific TaqMan probes (Raymond et al. 2005; Shi and Chiang 2005; Ro et al. 2006; SharbatiTehrani et al. 2008; Wang 2009; Varkonyi-Gasic and Hellens 2010). The latter assays are less expensive but have poorer detection limits and lower sequence specificity and accuracy than the TaqMan assay. All these methods, which do not rely on miRNA polyadenylation, can detect both $2^{\prime}-\mathrm{OH}$ and $2^{\prime}-\mathrm{OMe}$ forms but cannot differentiate between them.

Here we describe a new technology for detection of miRNA and other small RNAs, called miR-ID, which provides superior sensitivity and specificity without the need for expensive target-specific probes. miR-ID is comprised of three steps (Fig. 1): (1) circularization of the miRNA by a ligase; (2) reverse transcription of the circularized miRNA (RTC), producing cDNAs consisting of tandem repeats of the sequence complementary to the miRNA; and (3) qPCR amplification of segments of this multimeric cDNAs using $5^{\prime}$-overlapping primers and a nonspecific dye such as SYBR Green. No TaqMan probes or primer modifications (e.g., LNA) are required. The circular miRNA and multimeric cDNA templates each allow complete flexibility in positioning of their respective primers, including crossing the boundary between the end and the beginning of the miRNA sequence. MiR-ID is based on new findings that may have application beyond miR-ID: the ability to reverse transcribe small RNA circles and the use of $5^{\prime}$-overlapping primers for detection of repetitive sequences by qPCR. Each of the miR-ID steps can also be used individually in other miRNA-detection approaches such as microarray assays, in situ detection, isothermal amplification, and deep sequencing.
Although circularization of small RNAs (Step 1) has been previously considered in the context of other small RNA assays involving T4 RNA ligase, this reaction has mainly been regarded as a nuisance. For example, circularization blocks the attachment of the oligonucleotide adapters often used in the discovery and detection of small RNAs (Aravin and Tuschl 2005). In contrast, the miR-ID approach makes full use of circularization. A unique feature of miR-ID is its ability to detect small RNAs carrying both $2^{\prime}-\mathrm{OH}$ and $2^{\prime}-$ OMe termini and to discriminate these classes of RNAs from each other. This discrimination capability is based on our observation that CircLigase II and T4 RNA Ligase 1 can both effectively circularize the $2^{\prime}-\mathrm{OH}$ forms, but only CircLigase II can efficiently ligate the 2 '-OMe forms.

The reaction that constitutes Step 2 in miR-ID, the reverse transcription of circular miRNAs (RTC), has not previously been described, although primer extension reactions on small single-stranded DNA circles of comparable size using the Klenow fragment of DNA polymerase I have been reported (Frieden et al. 1999). RTC is less efficient than ordinary rolling-circle amplification (RCA) (Demidov 2002) and, therefore, cannot serve for direct detection of target sequences without the additional signal amplification provided here by qPCR. Although RCA and some other non-isothermal approaches to signal amplification have been previously applied to detection of miRNAs (Allawi et al. 2004; Hartig et al. 2004; Jonstrup et al. 2006; van Huffel et al. 2006; Cheng et al. 2009; Siva et al. 2009; Yao et al. 2009; Zhou et al. 2010), these methods were less sensitive and accurate than RT-PCR.

In miR-ID, the products of RTC, cDNAs containing tandem repeats, serve as templates for qPCR (Step 3). In this step, we employ $5^{\prime}$-overlapping primer pairs, an arrangement that allows each primer to be longer than half the length of the miRNA and confers additional sequence specificity. As a result, real-time detection of the PCR amplicon can be accomplished using a nonspecific dye such as SYBR Green instead of more costly target-specific (e.g., TaqMan) probes, without sacrificing specificity. Indeed, the performance appears to be superior to the currently available PCRbased methods for miRNA.

\section{RESULTS AND DISCUSSION}

The characterization and optimization of each of the three steps of the miR-ID procedure (Fig. 1) and the validation of the entire assay are described below. This approach is universally applicable to all different types of small RNAs that can be circularized and reverse-transcribed.

\section{Circularization of miRNAs by T4 RNA ligase and CircLigase}

The first step of miR-ID is the circularization of miRNAs by a ligase (Fig. 1A). The ability of T4 RNA ligase to circularize 


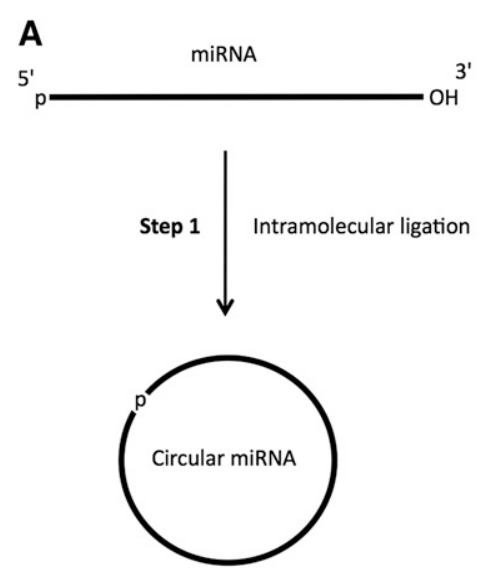

B
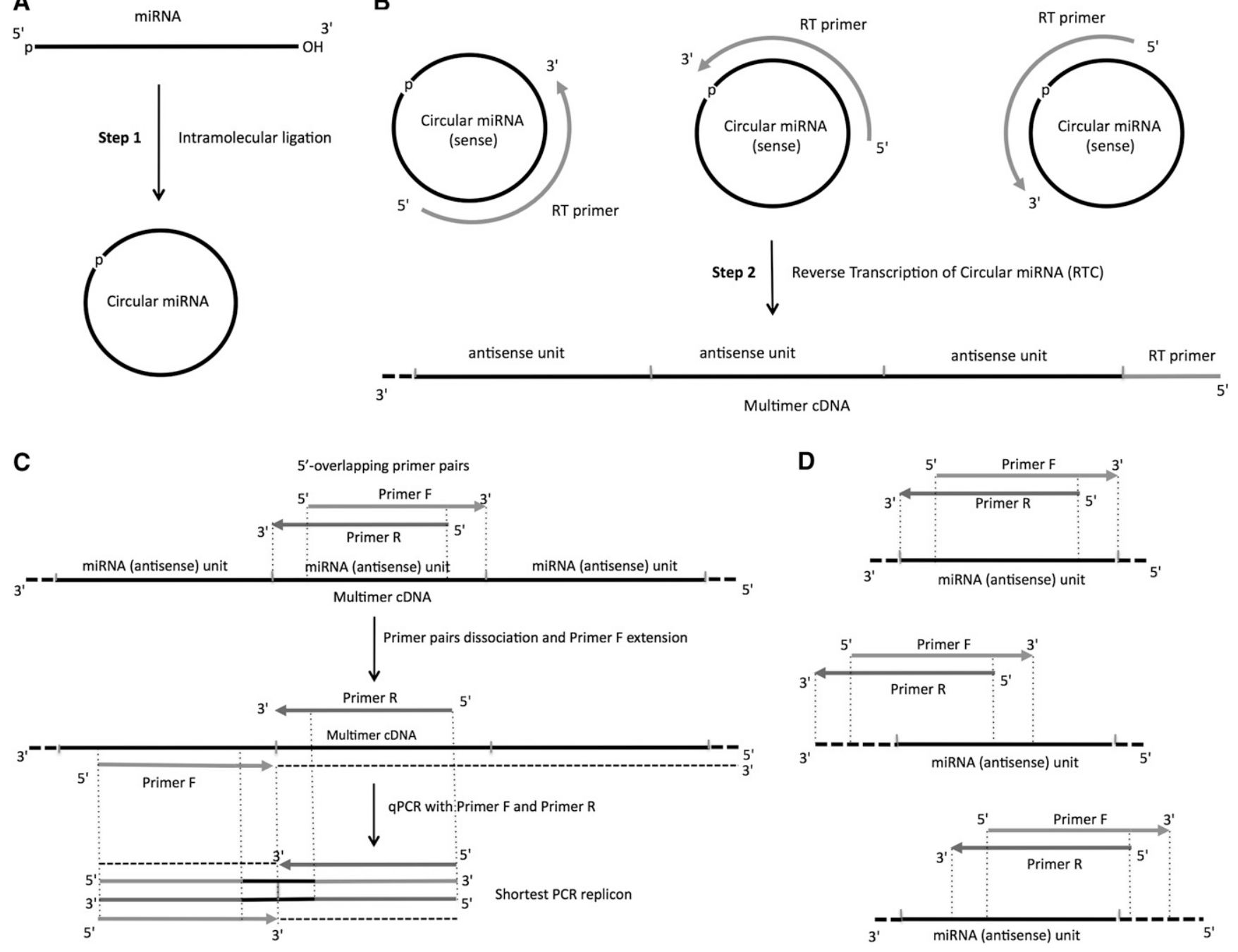

FIGURE 1. The miR-ID approach. (A) Circularization of a miRNA carrying $5^{\prime}$-phosphate $\left(5^{\prime}\right.$-p) and $3^{\prime}$-hydroxyl ( $3^{\prime}$-OH) ends by enzymatic ligation (Step 1). (B) Reverse transcription of the circularized miRNA (RTC) by extension of an RT primer, producing a cDNA consisting of tandem repeats of the sequence complementary to the miRNA (Step 2). Examples are shown of RT primers having various alignments relative to the ligation site. $(C)$ qPCR amplification of segments of the multimeric cDNA products of RTC using $5^{\prime}$-overlapping primers together with a nonspecific dye such as SYBR Green (Step 3). (D) Examples of possible alignments of the $5^{\prime}$-overlapping PCR primer pairs with monomer units of the multimeric cDNA, which include straddling the boundaries between these units.

RNAs having a $5^{\prime}$-phosphate $\left(5^{\prime}\right.$-p) and hydroxyl groups $\left(2^{\prime}\right.$ $\mathrm{OH} / 3^{\prime}-\mathrm{OH}$ ) at the $3^{\prime}$-end is well known (Uhlenbeck and Gumport 1982). Experiments with synthetic oligoadenylates suggested that this enzyme would most efficiently circularize small RNAs in the range 10-30 nt (Kaufmann et al. 1974). Thus, miRNAs with appropriate ends and lengths of 20-24 nt (Zamore and Haley 2005) make very good substrates for this reaction. The preferential circularization of miRNAs and other small RNAs would also effectively enrich any total RNA sample for this class of RNAs by converting them to a form that would be specifically amplified in the subsequent RT-PCR steps.

Early experiments with homopolynucleotides indicated that the efficiency of intramolecular ligation (circularization) by T4 RNA ligase depends mostly on RNA length rather than on its nucleotide composition (Silber et al. 1972; Cranston et al. 1974). However, no data related to the circularization of small RNAs with heterogeneous sequences of similar lengths have been reported. The rates of intermolecular reactions with T4 RNA ligase are strongly dependent on the identity of the terminal nucleotides, with $\mathrm{U}$ at the $3^{\prime}$-end resulting in the least efficient reaction (England and Uhlenbeck 1978; Ohtsuka et al. 1980; Romaniuk et al. 1982). Since a $U$ residue frequently occurs at the $3^{\prime}$-end of known miRNAs, we investigated the effect of this and other $3^{\prime}$-end nucleotides on the circularization (intramolecular ligation) of miRNAs.

For this purpose, we used four synthetic miRNAs: let-7b, let-7g, miR-16, and miR-23a, representing all possible 3'terminal nucleotides: $\mathrm{U}, \mathrm{A}, \mathrm{G}$, and C, respectively (Table 1). 
These miRNAs were ${ }^{32} \mathrm{P}$-phosphorylated at their $5^{\prime}$-ends and incubated with T4 RNA Ligase 1 (Rnl1) at $37^{\circ} \mathrm{C}$. The reaction products exhibited electrophoretic mobility consistent with the expected linear, circular, and $5^{\prime}$-adenylated forms of the miRNAs (Fig. 2A). The $5^{\prime}$-adenylated form is a standard intermediate product that can undergo further conversion to the circular form by Rnll (Wang et al. 2003; Silverman 2004). The circular forms of RNAs of this size migrate faster than the linear forms (Harrison and Zimmerman 1984; Ho and Shuman 2002), whereas the $5^{\prime}$-adenylated derivatives migrate $\sim 1 \mathrm{nt}$ slower than the unmodified linear forms (Ho and Shuman 2002). The miRNAs ending in $3^{\prime}-\mathrm{G}$ and $3^{\prime}-\mathrm{C}$ (lanes 9-12 and 13-16, respectively) exhibited the fastest kinetics, with circularization complete within 1 min (lanes 10,14), while for the miRNA with $3^{\prime}-\mathrm{U}$, the circularization was complete after 60 min (lane 4). The miRNA with $3^{\prime}$-A displayed the slowest kinetics, but its circular form was the dominant product at 60 min of incubation (lane 8). In summary, a 1-h treatment with Rnl1 provided robust circularization of all the tested miRNAs, but the kinetics were dependent on the $3^{\prime}$-terminal nucleotide in the order $\mathrm{G} \sim \mathrm{C}>\mathrm{U}>\mathrm{A}$.

As an alternative to T4 RNA ligase, we also tested CircLigase II (CLII, Epicentre). This enzyme is homologous to Rnll but was isolated from a thermophilic eubacterium (Blondal et al. 2003) and is marketed as a single-strand DNA ligase. Reaction with CLII at the recommended temperature of $60^{\circ} \mathrm{C}$ demonstrated very efficient circularization for all tested miRNAs within a 1-min reaction time (Fig. 2B, lanes $2,6,10,14)$. Surprisingly, with longer incubation times, we observed the partial reappearance of a band comigrating with the linear form of the miRNA, probably due to cleavage of the circularized miRNA under the reaction conditions. Thus, CLII can rapidly circularize miRNAs irrespective of their 3'-terminal nucleotide.

Although it has been shown that small RNAs having a 2'OMe modification at their $3^{\prime}$-ends could be intermolecularly ligated to oligonucleotide linkers by Rnl1, albeit with twofold to threefold lower efficiency relative to the 2'-OH RNAs (Barrio et al. 1978; Ebhardt et al. 2005; Yang et al. 2006), circularization of $2^{\prime}$-OMe RNAs has not been investigated. To study this reaction, we used synthetic versions of the same set of miRNAs (let-7b, let-7g, miR-16, and miR$23 a)$ in which the $2^{\prime}$-OMe modification was introduced at the variable $3^{\prime}$-terminal nucleotide. As with the $2^{\prime}-\mathrm{OH}$ miRNAs (Fig. 2A), the Rnl1 reaction products were identified as linear, circular, and adenylated forms of the miRNAs (Fig. 3A). The $5^{\prime}$-adenylated form was found to be the predominant product after incubation of the 2'-OMe miRNAs with Rnl1. For miRNAs ending with $U$ and A (lanes 1-8), no circular products were observed even after incubation for $60 \mathrm{~min}$, although the corresponding $2^{\prime}-\mathrm{OH}$ miRNAs underwent complete circularization under the same conditions. Only small amounts of circular products were detected for the miRNA ending with C (lanes 13-16).
TABLE 1. Sequences of miRNAs and corresponding miR-ID primers

\begin{tabular}{ll}
\hline Name & \multicolumn{1}{c}{ Sequence $\left(5^{\prime} \rightarrow 3^{\prime}\right)$} \\
\hline cel-lin-4 & UCCCUGAGACCUCAAGUGUGA \\
hsa-let-7a & UGAGGUAGUAGGUUGUAUAGUU \\
hsa-let-7b & UGAGGUAGUAGGUUGUGUGGUU \\
hsa-let-7c & UGAGGUAGUAGGUUGUAUGGUU \\
hsa-let-7d & AGAGGUAGUAGGUUGCAUAGU \\
hsa-let-7e & UGAGGUAGGAGGUUGUAUAGU \\
hsa-let-7g & UGCGGUAGUAGUUUGUACAGUA \\
mmu-miR-16 & UAGCAGCACGUAAAUAUUGGCG \\
mmu-miR-20 & UAAAGUGCUUAUAGUGCAGGUAG \\
mmu-miR-21 & UAGCUUAUCAGACUGAUGUUGA \\
mmu-miR-22 & AAGCUGCCAGUUGAAGAACUGU \\
hsa-miR-23a & AUCACAUUGCCAGGGAUUUCC \\
hsa-miR-127 & UCGGAUCCGUCUGAGCUUGGCU \\
ath-miR-171a & UGAUUGAGCCGCGCCAAUAUC \\
mmu-piR-1 & UGACAUGACACAGGUGCUCAGAUAGCUUU
\end{tabular}

Reverse transcription primers

lin-4RT

let-7a/c/d/g RT

let-7bRT

let-7eRT

miR-16RT

miR-20RT

miR-21RT

miR-22RT

miR-23aRT

miR-127RT

GTCTCAGGGA

CTACTACCTC

CTCAAACCAC

CTCCTACCTC

CGTGCTGCTA

CACTATAAGCACT

AGTCTGATAAGCT

CTGGCAGCTT

GGCAATGTGAT

ath-miR-162a

ath-miR-775

miR-171aRT

AGACGGATCC

GATGCAGAGG

GCACTGCTAG

GGCTCAATCA

sno-234RT

CAGTTCCAAAAG

qPCR DNA primers

lin-4Fwd

lin-4Rev

let-7aFwd

let-7aRev

let-7bFwd

let-7bRev

let-7cFwd

let-7cRev

let-7dFwd

let-7dRev

let-7eFwd

let-7eRev

let-7gFwd

let-7gRev

miR-16Fwd

miR-16Rev

miR-20Fwd

miR-20Rev

miR-21Fwd

miR-21Rev

miR-22Fwd

miR-22Rev

miR-23aFwd

miR-23aRev

miR-127Fwd

miR-127Rev

CTCAAGTGTGATCCCTGAG

AGGGATCACACTTGAGGTC

GAGGTAGTAGGTTGTATA

ACAACCTACTACCTCAAA

GTTTGAGGTAGTAGGTTGTG

AACCTACTACCTCAAACCAC

GAGGTAGTAGGTTGTATG

ACAACCTACTACCTCAAA

GTAGAGGTAGTAGGTTGC

ACCTACTACCTCTACTAT

TTGTATAGTTGAGGTAGG

ACCTCAACTATACAACCT

GAGGTAGTAGTTTGTACAGTA

TGTACAAACTACTACCTCATA

AGCACGTAAATATTGGCG

CCAATATTTACGTGCTGC

GCAGGTAGTAAAGTGCTTAT

AGCACTTTACTACCTGCACT

GATGTTGATAGCTTATCAGAC

TGATAAGCTATCAACATCAGT

CTGCCTGTTGAAGAACT

TTCTTCAACTGGCAGCT

TCACATTGCCAGGGAT

CCTGGCAATGTGATGG

GATCCGTCTGAGCTTGGCT

CAAGCTCAGACGGATCCGA

ath-miR-162aFwd AGT CGA TAA ACC TCT GCA TC 
TABLE 1. Continued

\begin{tabular}{ll}
\hline Name & \multicolumn{1}{c}{ Sequence $\left(5^{\prime} \rightarrow 3^{\prime}\right)$} \\
\hline ath-miR-162aRev & GCA GAG GTT TAT CGA CTG GA \\
ath-miR-775Fwd & GCAGTGCCATTCGATGT \\
ath-miR-775Rev & TCGAATGGCACTGCTAG \\
miR-171aFwd & CCGCGCCAATATCTGA \\
miR-171aRev & GATATTGGCGCGGCTC \\
sno-234Fwd & AAAAATTCGTCACTACCACTG \\
sno-234Rev & TGGTAGTGACGAATTTTTTT
\end{tabular}

The most efficient circularization was seen with the miRNA ending with $G$ (lanes 9-12), but even here the kinetics were significantly slower compared to the corresponding $2^{\prime}-\mathrm{OH}$ miRNA. To summarize, the presence of $2^{\prime}$-OMe modification significantly inhibited miRNA circularization by Rnll, and the extent of inhibition was dependent on the identity of the $3^{\prime}$-terminal nucleotide $(\mathrm{U} \sim \mathrm{A}>\mathrm{C}>\mathrm{G}$ ).

In contrast to Rnl1, the $2^{\prime}$-OMe modification had little effect on circularization by CLII (Fig. 3B). All 2'-OMe miRNAs were completely circularized by $15 \mathrm{~min}$ of incubation with CLII. The lesser sensitivity of CLII toward the $2^{\prime}$-modification is consistent with its ability to circularize both DNA and RNA with similar efficiency (Blondal et al. 2003), whereas Rnll is significantly less efficient toward DNA substrates (Uhlenbeck and Gumport 1982). In summary, both CLII and Rnl1 can circularize 2'-OH miRNAs, while only CLII can efficiently circularize 2 '-OMe miRNAs.

Secondary structures of RNAs that prevent appropriate contact between their ends can potentially interfere with circularization by Rnl1 (Uhlenbeck and Gumport 1982; Wang and Ruffner 1998). However, our analysis of the miRBase database of miRNAs (Griffiths-Jones 2010) indicated that the majority of miRNAs do not form stable secondary structures at $37^{\circ} \mathrm{C}$, the optimal temperature for Rnl1. Indeed, stable intrastrand structures might be expected to interfere with the ability of miRNAs to bind to their mRNA targets, and also with the ability of miRNA precursors to form hairpin structures that can be processed by Drosha and Dicer. Moreover, all known miRNAs were discovered by sequencing methods that depend on the ability of T4 RNA ligase to ligate them to DNA adapters (Aravin and Tuschl 2005). This fact implies that these miRNAs should be even better substrates for circularization by this enzyme since RNA circularization is significantly more efficient than intermolecular ligation of RNA, especially with DNA adapters (Uhlenbeck and Gumport 1982). For the few miRNAs that do form stable secondary structures, the use of CLII allows circularization to proceed at $60^{\circ} \mathrm{C}$, where such structures are strongly destabilized.

\section{Reverse transcription of circular miRNAs}

The second step of miR-ID is the reverse transcription of circular miRNAs (RTC) (Fig. 1B). There have been no reports to date describing the ability of small circular RNAs to serve as templates for primer extension by an RNA-dependent DNA polymerase (reverse transcriptase), although similar reactions with DNA-dependent DNA polymerases have been described for single-stranded DNA circles of 34 or fewer nucleotides (Fire and Xu 1995; Liu et al. 1996; Frieden et al. 1999).

Small circular nucleic acid templates, whether DNA or RNA, impose several structural constraints on polymerase action. First, the stiffness of the duplex formed by the circular template and a primer makes the formation of duplexes longer than half the size of the template unlikely (i.e., $10 \mathrm{bp}$ for a 21-nt template). The primer extension of a circular template occurs through a rolling circle mechanism (RCA). In contrast to RCA of larger circles, $3^{\prime}$-extension of a primer hybridized to a small RNA circle requires simultaneous unwinding at its $5^{\prime}$-end. Also, internal base-pairing within a circle, creating a dumbbell-like structure, may hinder both hybridization and extension of primers. In addition, the polymerase must be able to bind and act on the compact

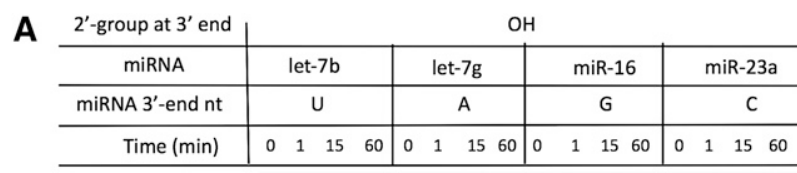
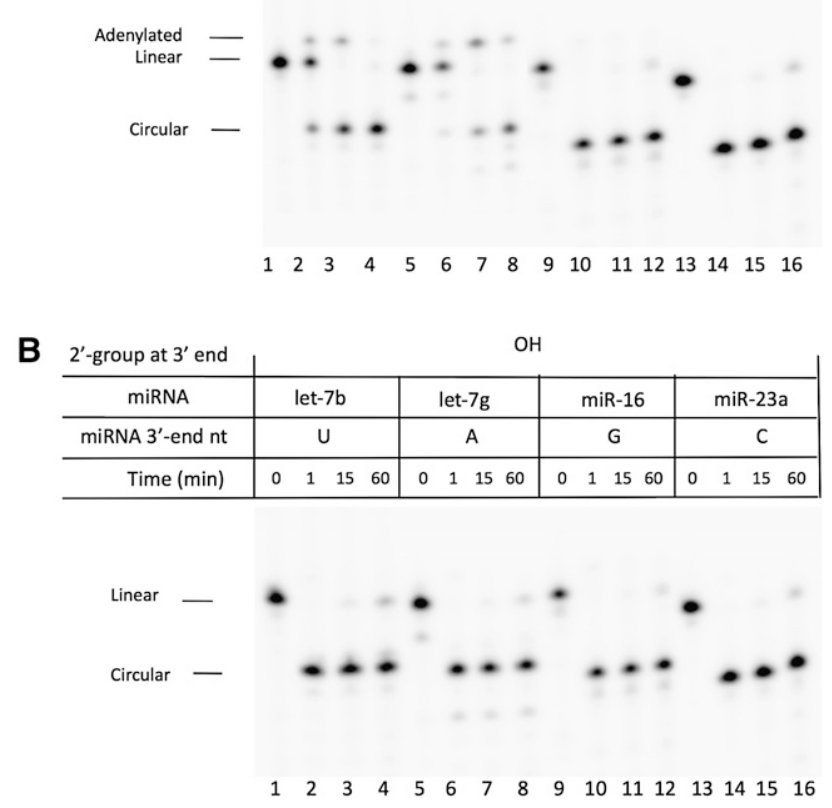

FIGURE 2. Circularization of miRNAs having nonmethylated $3^{\prime}$ ends ( $2^{\prime}-\mathrm{OH}$ miRNAs). (A) Using T4 RNA ligase 1 (Rnll) at $37^{\circ} \mathrm{C}$. (B) Using CircLigase II (CLII) at $60^{\circ} \mathrm{C} .80 \mathrm{nM}$ synthetic miRNAs (let$7 \mathrm{~b}$, let-7g, miR-16, and miR-23a, which have four different nucleotides with $2^{\prime}-\mathrm{OH}$ and $3^{\prime}-\mathrm{OH}$ at their $3^{\prime}$-termini), were ${ }^{32} \mathrm{P}$-labeled at their $5^{\prime}$-ends and then circularized using one or the other ligase. Aliquots were taken at $0,1,15$, and 60 min of ligation and analyzed on a denaturing $15 \%$ polyacrylamide gel. The reaction products include the unmodified linear, $5^{\prime}$-adenylated linear, and circular forms of the miRNAs as shown. 
A

\begin{tabular}{|c|c|c|c|c|}
\hline $2^{\prime}$-group at $3^{\prime}$ end & \multicolumn{4}{|c|}{ OMe } \\
\hline miRNA & let-7b & let-7g & miR-16 & miR-23a \\
\hline miRNA $3^{\prime}$-end nt & u & A & G & c \\
\hline Time (min) & $\begin{array}{llll}0 & 1 & 15 & 60\end{array}$ & 1560 & 1560 & $15 \quad 60$ \\
\hline
\end{tabular}

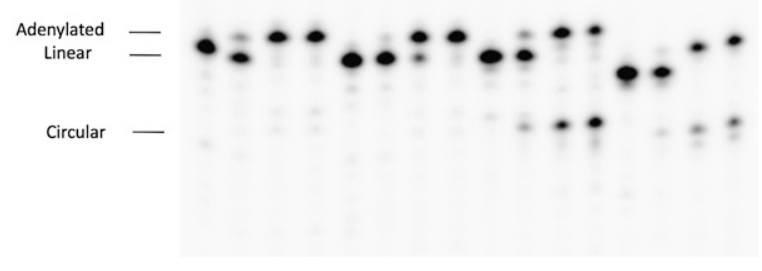

$\begin{array}{llllllllllllllll}1 & 2 & 3 & 4 & 5 & 6 & 7 & 8 & 9 & 10 & 11 & 12 & 13 & 14 & 15 & 16\end{array}$

\begin{tabular}{|c|c|c|c|c|}
\hline $2^{\prime}$-group at $3^{\prime}$ end & \multicolumn{4}{|c|}{$\mathrm{OMe}$} \\
\hline miRNA & let-7b & let-7g & miR-16 & miR-23a \\
\hline miRNA $3^{\prime}$-end nt & U & A & G & C \\
\hline Time (min) & $\begin{array}{lll}1 & 15 & 60\end{array}$ & $\begin{array}{llll}0 & 1 & 15 & 60\end{array}$ & $\begin{array}{llll}0 & 1 & 15 & 60\end{array}$ & $\begin{array}{llll}0 & 1 & 15 & 60\end{array}$ \\
\hline
\end{tabular}

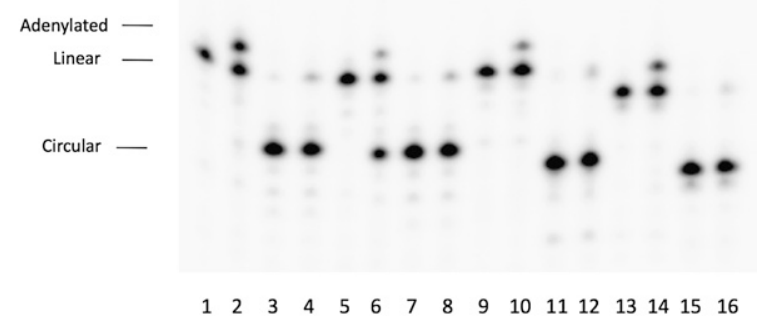

FIGURE 3. Circularization of miRNAs having a $2^{\prime}$-oxymethyl modification at their $3^{\prime}$-ends ( $2^{\prime}$-OMe miRNAs). (A) Using T4 RNA ligase 1 (Rnl1) at $37^{\circ} \mathrm{C}$. (B) Using CircLigase II (CLII) at $60^{\circ} \mathrm{C} .80 \mathrm{nM}$ synthetic miRNAs (let-7b, let-7g, miR-16, and miR-23a), which have four different nucleotides with $2^{\prime}$-OMe and $3^{\prime}-\mathrm{OH}$ at their $3^{\prime}$-termini, were ${ }^{32} \mathrm{P}$-labeled at their $5^{\prime}$-ends and then circularized using either ligase. Aliquots were taken at $0,1,15$, and 60 min during the courses of the ligation reactions and analyzed on a denaturing $15 \%$ polyacrylamide gel. The reaction products include the unmodified linear, 5 '-adenylated linear, and circular forms of the miRNAs as shown.

structure of the RNA circle. In the case of circular DNAs, the only DNA polymerase known to accept circles smaller than $24 \mathrm{nt}$ as templates is the Klenow fragment (Frieden et al. 1999). This polymerase did not accept circular miRNAs as templates in our experiments (data not shown).

However, we found that some engineered versions of Maloney murine leukemia virus reverse transcriptase (MMLV RT) could extend DNA primers complementary to miRNA circles. SuperScript II (SSII; Invitrogen), which lacks RNase H activity, was found to be most efficient. As an example, Figure 4 shows the reverse transcription of circular miR-127 (see sequence in Table 1) by SSII at $42^{\circ} \mathrm{C}$ in the presence of $\left[\alpha-{ }^{32} \mathrm{P}\right] \mathrm{dATP}$. The ${ }^{32} \mathrm{P}$-labeled products of this reaction had a ladder-like pattern with a maximum length of the synthesized multimers of $\sim 330 \mathrm{nt}$, equivalent to about 15 repeats of a sequence complementary to the miRNA. These results indicate comparatively low RCA efficiency due to limited processivity. The observed periodic patterns of the RCA products (Fig. 4) is probably due to binding of a new RT primer after the extending primer moves to the opposite side of the circular template, inhibiting further extension. Interestingly, there was no significant difference in the results obtained with a 10-nt versus a 19-nt RT primer (Fig. 4). This can be explained in terms of elongation being rate-limiting and the stiffness of the duplex limiting the region of primertemplate pairing to $\sim 10 \mathrm{bp}$ for circles of $\sim 22 \mathrm{nt}$. We decided to use 10-nt RT primers because the longer primers do not provide higher RTC efficiency. Also, shorter RT primers mixed in a multiplex reaction are less likely than longer primers to form primer dimers; and they should not interfere with the subsequent PCR reactions, as the latter are performed at higher temperatures where short RT primers cannot anneal and be extended.

The natural RNAse $\mathrm{H}$ activity of reverse transcriptases might be expected to prevent the synthesis of multimeric cDNA by RTC due to cleavage of the circular RNA template. However, we found that some MMLV RT variants having RNase $\mathrm{H}$ activity can, indeed, reverse-transcribe circular miRNAs (data not shown). Because the RNase $\mathrm{H}$ activity of MMLV RT requires a DNA-RNA duplex of at least $14 \mathrm{bp}$ (Ben-Artzi et al. 1993), which, as we have discussed, exceeds the length of duplex that can be formed on a 22-nt circle, the small circular RNA template is evidently not cleaved, and RCA can proceed.

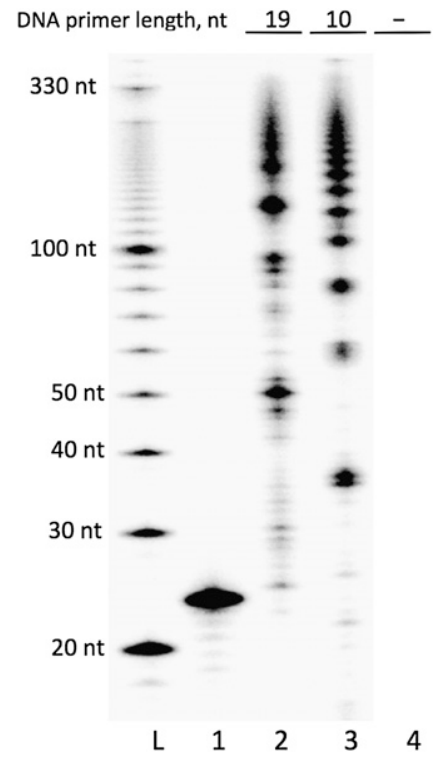

FIGURE 4. Reverse transcription of a circular miRNA template (RTC). Circularized synthetic miR-127 miRNA (80 nM) was used as template for SSII reverse transcriptase with 10- and 19-nt RT primers $(1 \mu \mathrm{M})$ in the presence of $\left[\alpha-{ }^{32} \mathrm{P}\right] \mathrm{dATP}$. The resulting ${ }^{32} \mathrm{P}-$ labeled primer-extension products were analyzed on a denaturing $12 \%$ polyacrylamide gel. (Lane $L$ ) A $5^{\prime}-{ }^{32} \mathrm{P}$-labeled 10 -bp DNA ladder. (Lane 1) Linear $5^{\prime}{ }^{32} \mathrm{P}$-labeled miR-127 as a control. (Lanes 2,3) The extension products of 19- and 10-nt primers, respectively. (Lane 4) A negative control in which the RTC reaction with the 10-nt primer was carried out without the miRNA template. 
In general, the reverse transcription of circular miRNAs (RTC) provides a lower yield and shorter lengths of multimer products than ordinary RCA (Demidov 2002). For this reason, RTC does not provide enough amplification to allow direct detection of endogenous miRNAs without additional signal amplification, e.g., by PCR. However, RTC has certain advantages in comparison to the ordinary RT step in RT-PCR assays. First, it provides some pre-amplification, which allows the use of smaller samples when analyzing for low-abundance miRNAs. Second, it produces a cDNA containing tandem repeats that can be amplified by PCR using 5 '-overlapping primer pairs (see below). Third, it provides unmatched flexibility in the choice of RT primer sequences, as they can be aligned anywhere along the circle, including across the ligation boundary (Fig. 1B). This flexibility is important for optimizing the efficiency and specificity of reverse transcription for each miRNA sequence and for avoiding the formation of RT primer dimers when performing RT in multiplex format.

\section{PCR amplification of multimeric miRNA sequences using $5^{\prime}$-overlapping primers}

The third step of miR-ID is the qPCR amplification of the multimeric cDNAs (products of RTC) using $5^{\prime}$-overlapping primers (Fig. 1C,D). PCR primers that overlap at their $5^{\prime}$-ends have been previously used for site-specific DNA mutagenesis, splicing and shuffling of DNA sequences (Vallejo et al. 1994). In this study, we described application of such primers for amplification of short repetitive sequences. Our $5^{\prime}$-overlapping primer pairs contain forward and reverse miRNA-specific primers, each 17 to $20 \mathrm{nt}$ long-slightly shorter than the miRNAs themselves-with a 15-16-bp overlap (complementarity) at their $5^{\prime}$-ends and single-stranded overhangs of 2-4 nt at their $3^{\prime}$-ends. Each partner of the primer pair forms a more thermo-stable duplex with its respective cDNA template sequence than with its partner primer. As schematically shown in Figure $1 \mathrm{C}$, the primer pair dissociates under PCR condition and the forward primer extends first, followed by exponential PCR amplification using both primers.

All PCR assays show some variability of signal amplification efficiency and specificity due to variable affinities of primers for their templates (Bracho et al. 2004). This bias cannot be completely eliminated, but it can be minimized through optimization of primers. As with the circular RNA templates in the RTC step, the multimeric cDNA templates allow for complete flexibility in the positioning of the PCR primers, which may include straddling the boundaries between these units (Fig. 1D). This flexibility provides options for matching the $T_{\mathrm{m}}$ of the primers and optimizing their sequence specificity that are not available for short monomeric templates used in current RT-PCR microRNA assays.

To characterize the products of the PCR step in miR-ID, circularized let-7b miRNA was reverse-transcribed by SSII using an RT primer of $18 \mathrm{nt}$ (Primer R), which was complementary to nucleotides $1-18$ of let-7b (see Table 1 for sequences), and then amplified by PCR. Linear let-7b was used as a control template. Because of the positioning of Primer R, it could reverse-transcribe circular miRNA but not its linear form (Fig. 5A). In the PCR step, the same Primer R was used as the reverse PCR primer, together with an 18-nt forward primer (Primer F). The 5'-ends of Primers $\mathrm{F}$ and $\mathrm{R}$ overlapped by $15 \mathrm{nt}$, leaving 3-nt overhangs at their 3 '-ends. As expected, the linear miRNA did not yield any products after 20 cycles of PCR, while the circular miRNA generated multimer (concatamer) products (Fig. 5B) with longer multimers generated with increasing numbers of PCR cycles (lanes 1,4). Surprisingly, melting
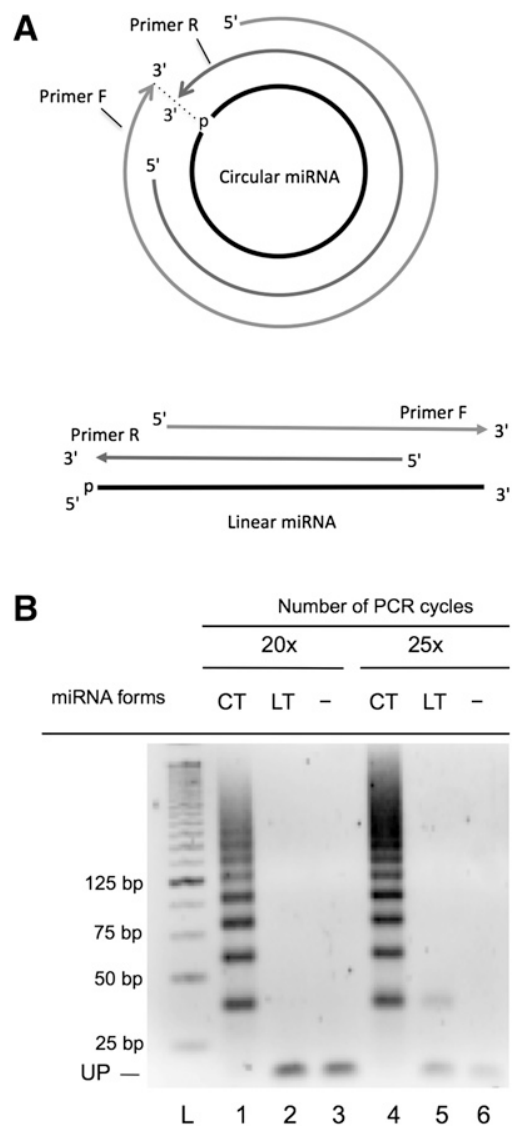

FIGURE 5. RT-PCR of circularized miRNA by a pair of $5^{\prime}$-overlapping primers yields multimeric amplicons. (A) Alignment of $5^{\prime}$ overlapping primers with circular (CT) and linear (LT) forms of an miRNA. (B) Synthetic linear and circularized let-7b miRNAs $(2 \mathrm{nM})$ were used as templates for reverse transcription by SSII using Primer $\mathrm{R}(80 \mathrm{nM})$, followed by PCR using the same Primer R together with Primer F. Primer R (18 nt) was complementary to nucleotides 1-18 of let-7b miRNA, while Primer F (18 nt) corresponded to nucleotides 4-21 of let-7b. The $5^{\prime}$-ends of Primers $F$ and $R$ have 15 nt of complementarity, leaving 3-nt overhangs at their $3^{\prime}$-ends when hybridized to each other. The PCR products were analyzed on a $3 \%$ agarose gel. Lanes 1-3 correspond to 20 cycles, and lanes 4-6 to 25 cycles of PCR. (Lanes 3,6) Negative controls, in which the RT-PCR reactions were carried out without the miRNA templates. (Lane $L$ ) A DNA ladder. (UP) Unused PCR primers. 
curves generated at the end of a real-time $\mathrm{qPCR}$ reaction (see below) showed a single sharp transition (specific for each miRNA) despite the variable numbers of repeats represented in the PCR products.

The synthesis of longer PCR products, observed in Figure $5 \mathrm{~B}$, presumably occurs through the concatamer chain reaction (CCR) (White et al. 1991; Hemat and McEntee 1994). In this process, DNA concatamers can serve as both templates and primers for subsequent PCR cycles. Upon thermal denaturation and re-annealing, multimeric single strands can anneal to each other such that they are shifted by one or more repeat units, leaving single-stranded extensions. Extension of recessed $3^{\prime}$-ends results in longer multimers, and each PCR cycle results in progressively longer multimers. CCR competes with ordinary PCR and may predominate when the PCR primers are in limiting amounts. This process, combined with ordinary PCR, can provide stronger signal amplification (and, therefore, higher sensitivity) than conventional PCR (Zhang et al. 1998). Since CCR is not dependent on initial primer concentration, we were able to reduce the concentration of 5 '-overlapping PCR primers to $150 \mathrm{nM}$ (in comparison to the $0.5-1.5 \mu \mathrm{M}$ used in ordinary PCR reactions) without reducing the sensitivity of the assay.

Because of the substantial complementarity of our $5^{\prime}$ overlapping primers, they resemble previously described "double-stranded" PCR primers (Li et al. 2002; Kong et al. 2004). However, the latter primers had only one strand extendable; the other strand was blocked at its $3^{\prime}$-end. In contrast, both primers in our $5^{\prime}$-overlapping primer pairs are extendable. The double-stranded structure of our primers provides several advantages over ordinary single-stranded primers. First, it can act as a stringency element, enhancing the sequence specificity of PCR by reducing nonspecific amplification during PCR ( $\mathrm{Li}$ et al. 2002). Second, since a duplex structure must be melted before primers can hybridize to complementary target strands, it provides a "hot start" for every PCR cycle, minimizing nonspecific primer annealing and extension at low temperatures (Kong et al. 2004). Third, in multiplex PCR assays, the duplex structure of primer pairs limits their interaction with primers specific to other templates, providing lower background and allowing higher levels of multiplexing.

\section{Sensitivity and dynamic range of the miR-ID assay}

After testing each individual step as described above, we combined them into the miR-ID assay and compared its performance with the TaqMan microRNA assay (Chen et al. 2005).

First, we tested sensitivity and dynamic range. For this purpose, we chose lin-4, previously used as a reference miRNA in characterizing the TaqMan assay (Chen et al. 2005), and constructed standard dilution curves for both the TaqMan and miR-ID assays (Fig. 6). For miR-ID, synthetic lin-4 at various concentrations over the range 20 aM to $200 \mathrm{pM}$ was consecutively subjected to circularization by Rnl1 and reverse transcription by SSII, followed by qPCR using optimized lin-4-specific primers and SYBR Green for detection of amplified products (for details, see legend to Fig. 6). The TaqMan assay was carried out using the lin-4-specific primers and the TaqMan probe obtained from Applied Biosystems according to the recommended protocol. Both methods provided the same detection limit (about 10 miRNA copies), but miR-ID was found to be about 32 times $\left(2^{5}\right)$ more sensitive than the TaqMan assay across a dynamic range of 8 orders of magnitude in concentration, as shown by the lower $C t$ values $(\Delta C t \sim 5)$ with miR-ID (Fig. 6). This result is especially remarkable since currently available RT-PCR miRNA assays that use SYBR Green have a detection limit 10-1000 times lower than the TaqMan assay. This limitation is a result of a higher background signal due to the inability of the dye to distinguish between specific and nonspecific products accumulating during PCR (Raymond et al. 2005; Sharbati-Tehrani et al. 2008; Wang et al. 2009; Yang et al. 2009). The use of SYBR Green, which is widely available and less expensive than TaqMan probes (Wang 2009), significantly reduces the

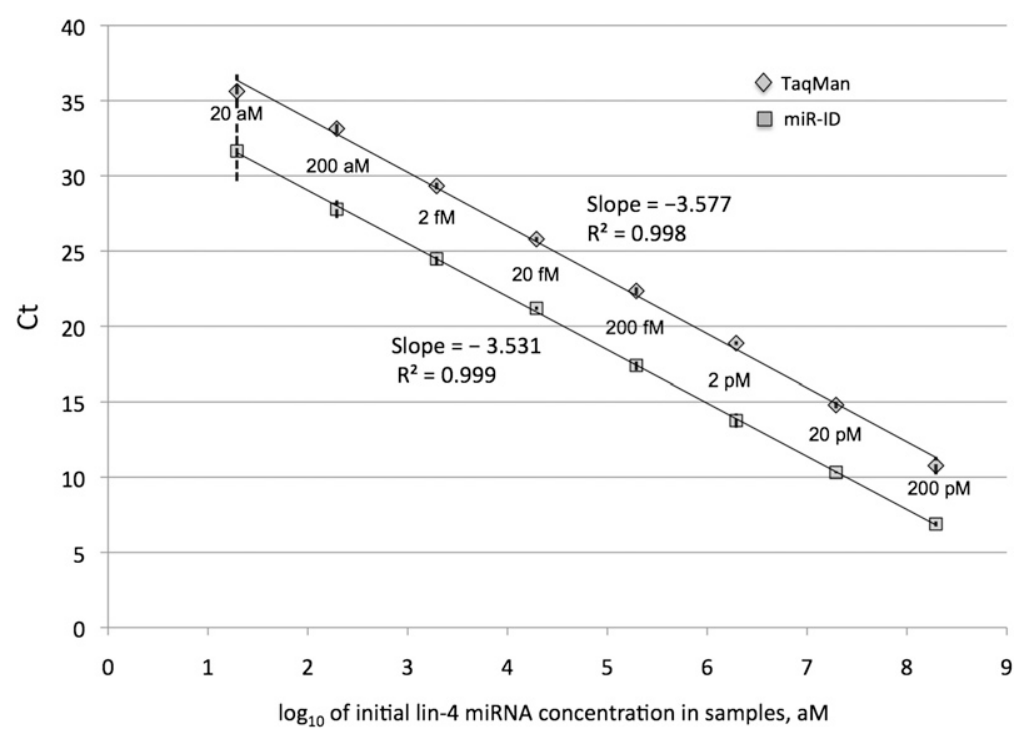

FIGURE 6. Side-by-side comparison of sensitivity, detection limit, and dynamic range for the miR-ID and TaqMan microRNA assays. Standard curves for both assays were generated for a dilution series from $200 \mathrm{pM}$ to $20 \mathrm{aM}$ of synthetic lin-4 miRNA for either the miR-ID and the TaqMan assays. The data for the TaqMan assay correspond closely to the previously reported standard curve (Chen et al. 2005), taking into account that in the latter publication the concentrations of lin- $4(1.3 \mathrm{aM}$ to $13 \mathrm{pM})$ represented inputs into the PCR reactions rather than inputs into RT reactions as shown here. 
experimental cost for the miR-ID assay without sacrificing the detection limit and sensitivity.

Using synthetic let-7b miRNA, we demonstrated that the use of either Rnll or CLII in the ligation step resulted in the same sensitivity and detection limit for the overall assay (Fig. 7).

The miR-ID protocol described in Materials and Methods allows the simultaneous detection of a number of miRNAs. Steps 1-2 were performed in multiplex and Step 3 in singleplex format, but with all qPCR reactions done in parallel under the same conditions. Multiplexing for Steps 1 and 2 has been tested for up to 20 miRNAs with no indication that a limit was being approached.

In the present paper, we describe assays for 15 miRNAs as examples to illustrate the various features of miR-ID. Although the design and optimization of RT and PCR primers were based on common considerations such as $T_{\mathrm{m}}$ matching and avoiding overlaps between primers at their 3 '-ends, features unique to the circular and multimeric templates and $5^{\prime}$-overlapping primers were also considered. The sequences of all primers are shown in Table 1.

Standard miR-ID dilution curves generated for different miRNAs vary slightly from each other, reflecting some inevitable bias at every enzymatic step. But the majority $(>80 \%)$ of these variations for miR-ID were found to be within $\Delta C t \sim 5$ (data not shown), which is similar to the variability reported for TaqMan microRNA assays (Ambion 2008; Mitchell et al. 2008; Git et al. 2010). These variations result in different $C t$ values for given amounts of different

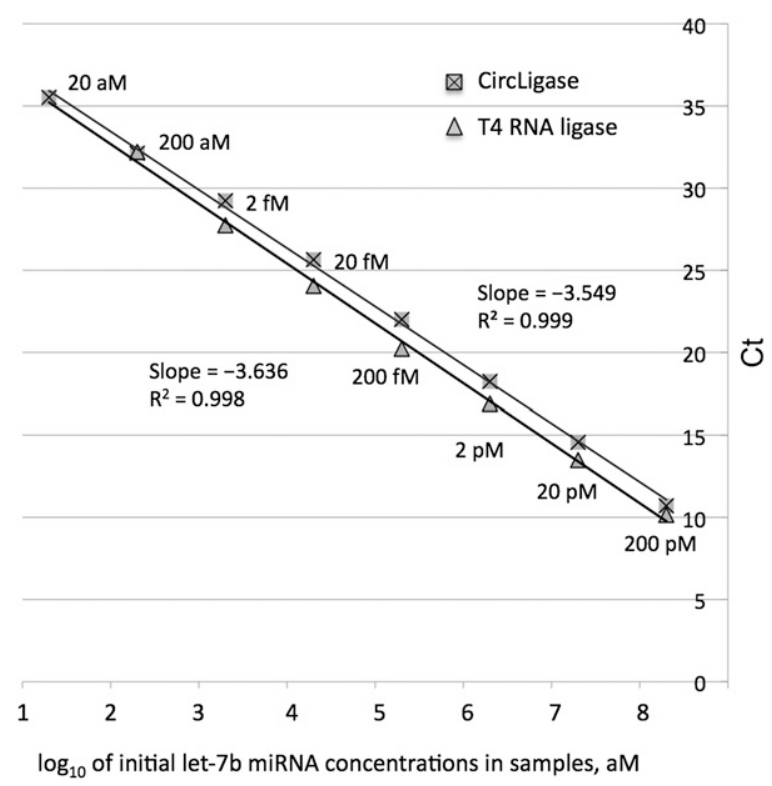

FIGURE 7. Side-by-side comparison of circularization of $2^{\prime}-\mathrm{OH}$ miRNA by ligases Rnll and CLII. Synthetic let-7b miRNA having $5^{\prime}-\mathrm{p}$ and $2^{\prime}-\mathrm{OH} / 3^{\prime}-\mathrm{OH}$ ends was used in this example. Standard curves were generated for a dilution series from $200 \mathrm{pM}$ to $20 \mathrm{aM}$ let$7 \mathrm{~b}$ for miR-ID assays in which either T4 RNA ligase 1 (Rnl1) or CircLigase II (CLII) was used in the circularization step, followed by the usual RTC and qPCR steps.
miRNAs. Such variability does not affect the results of relative expression profiling of the same miRNAs across different samples. However, if the goal is absolute quantification of individual miRNAs or relative expression profiles of various miRNAs in the same sample, then standard dilution curves should be generated for each miRNA of interest.

Of course, standard curves, which are generated in vitro using synthetic miRNAs, are useful for quantifying naturally occurring miRNAs in total RNA extracted from biological samples only if $C t$ values are not affected by the presence of other RNAs. To test this, we compared standard dilution curves for synthetic miR-127 assayed by miR-ID either in the presence or absence of $20 \mathrm{ng}$ of total RNA from Jurkat cells, which do not express miR-127 (Yu et al. 2006) (20 ng of total RNA exceeds the amount usually used for TaqMan RT-qPCR microRNA assays [ABI 2010]). The results with and without total RNA are virtually superimposable (Fig. 8), indicating that the presence of total RNA from Jurkat cells has no effect on the miR-ID assay for miR-127.

\section{Sequence specificity}

The sequence specificity of the miR-ID assay was evaluated using a standard set of five let-7 miRNA isoforms: let-7a, let-7b, let-7c, let-7d, and let-7e (Fig. 9A). The individual miRNAs were circularized and then reverse-transcribed using a "universal" RT primer (7abcdRT) for let-7a, b, c, and d isoforms and a specific RT primer (7eRT) for let-7e. Isoform-specific PCR primer pairs having a 15-nt overlap at their $5^{\prime}$-ends and 3-nt overhangs at their $3^{\prime}$-ends were used for qPCR (Table 1). Aliquots from each RT reaction were tested in a matrix of real-time qPCR reactions, whereby every miRNA isoform was subjected to qPCR with every isoform-specific primer set. For example, the RT product of let-7a was used as the template for APCR with $5^{\prime}$-overlapping primer pairs specific for let- $7 \mathrm{a}$, let-7b, let$7 \mathrm{c}$, let-7d, and let-7e in five separate reactions. For each primer set, the difference in $C t$ value for its intended isoform and the other isoforms was converted into a linear percentage scale, with the fully matched reaction normalized to $100 \%$. All isoforms were distinguished from one another with virtually no cross-reaction, even among isoforms differing by a single nucleotide (e.g., let-7b and let$7 \mathrm{c}$ ), as shown by percentage values above each isoform label (Fig. 9B). Discrimination between the miRNA isoforms was better than for currently used RT-qPCR assays, including the TaqMan microRNA assay (see Chen et al. 2005; Raymond et al. 2005; Qiagen 2009).

These results also demonstrate that sequence specificity can be provided at the PCR step even when a "universal" (i.e., nonspecific) RT primer was used in the RTC step. The duplex structure of our $5^{\prime}$-overlapping primers can potentially enhance the sequence specificity of the PCR step by 


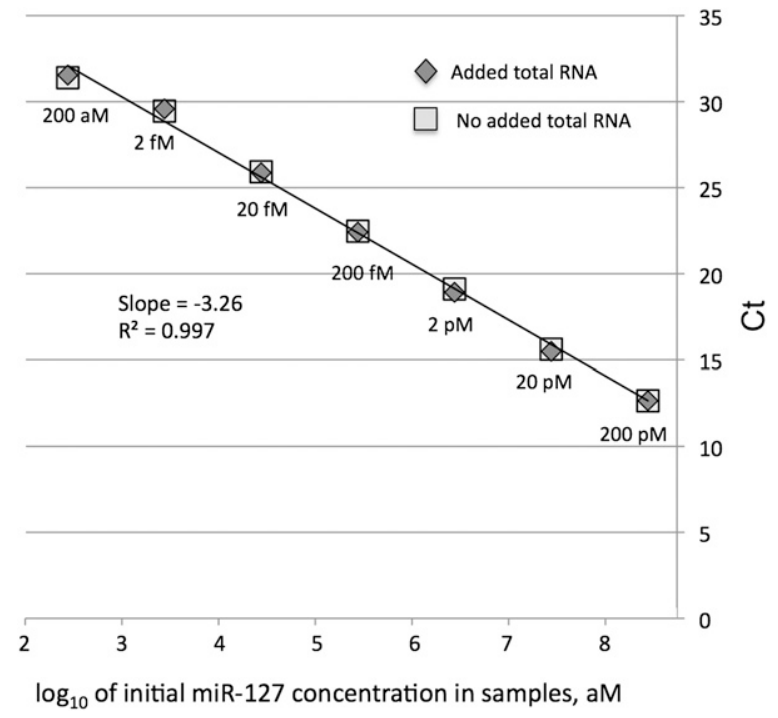

FIGURE 8. Sensitivity and detection limit of an individual miRNA are not affected by the presence of total cellular RNA. Synthetic miR127 miRNA having $5^{\prime}-\mathrm{p}$ and $2^{\prime}-\mathrm{OH} / 3^{\prime}-\mathrm{OH}$ ends was used in this example. Standard curves were generated for a dilution series from $200 \mathrm{pM}$ to $200 \mathrm{aM}$ miR-127 for miR-ID assays performed either in the absence (squares) or the presence of $20 \mathrm{ng}$ of total cellular RNA (diamonds). The total RNA was extracted from Jurkat cells, which do not express miR-127.

discriminating against any partially complementary nontarget sequences present in samples, as discussed above. For mismatch discrimination, the $5^{\prime}$-overlapping primers should be designed to form more thermostable duplexes with intended target sequences than with sequence variants. This feature of the miR-ID assay eliminates the need for target-specific (e.g., TaqMan) probes to achieve higher sequence specificity than is provided by ordinary SYBR Green-based assays.

\section{Differentiation between mature and precursor miRNAs}

Specific detection of mature miRNAs and differentiation from their precursors (pre-miRNAs) is important, since only the mature form is thought to be directly involved in gene silencing (O'Hara et al. 2009). In this respect, TaqMan microRNA assays rely on the higher affinity of their stemloop RT primer for the 3 '-end of the mature miRNA sequence than for the same sequence within the hairpin structure of the corresponding pre-miRNA form (Chen et al. 2005). The extent of such affinity-based discrimination varies dramatically depending on pre-miRNA structure and sequence (Chen et al. 2005; Wan et al. 2010). In contrast, miR-ID can reliably discriminate these two miRNA forms at both RT and PCR steps by using primers that cross boundaries between miRNA sequences repeats targeting specifically one form over another. To illustrate this, we circularized synthetic let$7 \mathrm{~b}$ and pre-let-7b RNAs using Rnl1, then performed the RT and qPCR steps using RT and $5^{\prime}$-overlapping PCR primers specific for the mature form (Table 1). The observed $\Delta C t$ of about 12 between the mature miRNA and pre-miRNA corresponds to an $\sim 4000$-fold $\left(2^{12}=4096\right)$ discrimination between these two RNA forms (data not shown). This discrimination implies that, even at equal concentration, the pre-miRNA would contribute $<0.0025 \%$ to the background signal when assaying for the mature miRNA.

Although the specific detection of mature miRNAs is the ultimate goal of most current expression profiling assays, there is also growing interest in quantification specifically of pre-miRNAs (Lee et al. 2008; O'Hara et al. 2009). The miRID assay can specifically detect pre-miRNAs and differentiate

$\begin{array}{llc}\text { A } & \text { let } & 5^{\prime}-3^{\prime} \\ & 7 \mathrm{a} & \text { UGAGGUAGUAGGUUGUAUAGUU } \\ & 7 \mathrm{~b} & \text { UGAGGUAGUAGGUUGUGUGGUU } \\ & \text { 7c } & \text { UGAGGUAGUAGGUUGUAUGGUU } \\ & \text { 7d } & \text { AGGAGGUAGUGGUUGCAUAGU } \\ & \text { 7e } & \text { UGAGGUAGGAGGUUGUAUAGU }\end{array}$
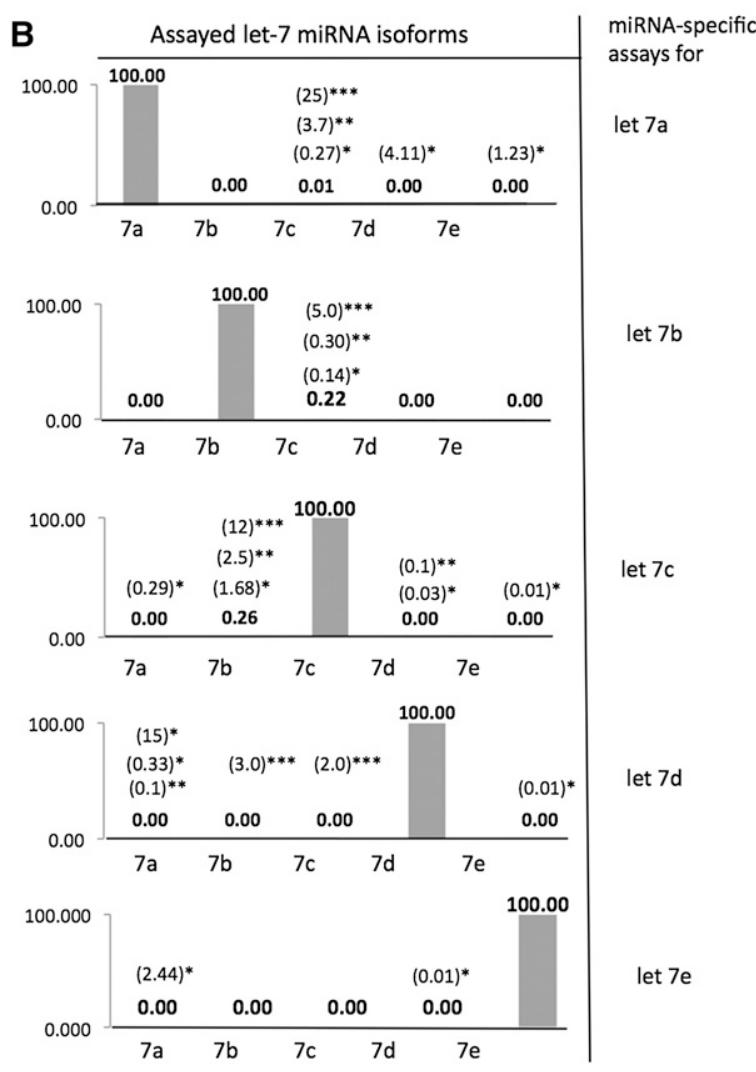

FIGURE 9. Discrimination of let-7 miRNA isoforms. (A) Sequences of selected members of let-7 miRNA family. The nucleotide differences between let-7a and the other isoforms are underlined. $(B)$ Relative detection (in percent) of let-7 isoforms by miR-ID assays, in which every individual isoform was assayed with every isoformspecific primer pair. For each assay, the difference in $C t$ value for its intended isoform and the other isoforms was converted into a linear percentage, with the fully matched reaction (diagonal values) made equal to $100 \%$. (Bold numbers) miR-ID; (numbers in parentheses) published values (other than 0.0) for QIAGEN's miScript/ SYBR Green $\left({ }^{*}\right)$, ABI's TaqMan $\left({ }^{* *}\right)$, and LNA/SYBR Green $\left({ }^{* *}\right)$ miRNA RT-qPCR assays. 
them from the mature miRNAs by using precursor-specific RT and/or 5'-overlapping PCR primers. Since circular premiRNAs will contain sequences not found in circular miRNAs, miRNA-specific RT (or PCR) primers can easily be designed such that their $3^{\prime}$-ends cross the ligation site on the circular miRNA. Such primers can be extended on circular miRNA templates but not on the corresponding pre-miRNAs, which are not complementary to the $3^{\prime}$-ends of the primers. Alternatively, RT primers targeting the premiRNA loop sequence, which is absent in the mature miRNA, can be used for specific RTC of pre-miRNAs.

\section{Detection of endogenous miRNAs}

After demonstrating the basic features of miR-ID in experiments performed on synthetic miRNAs, we tested the method for detection of endogenous miRNAs.

In one example, various amounts of either total RNA extracted from Jurkat cells or lysates of these cells (without RNA extraction) were treated with CLII. The circularized RNAs were reverse-transcribed and subjected to qPCR using let-7b-specific RT and $5^{\prime}$-overlapping PCR primers (see sequences in Table 1). The results demonstrated robust detection of endogenous let-7b from as little as $20 \mathrm{pg}$ of total RNA (Fig. 10), comparable to the amount of RNA from a single cell (Chen et al. 2005; Yu et al. 2006). The detection of let-7b in purified total RNA from the same cells provided only marginally better sensitivity $(\Delta C t \sim 2)$ compared to the crude cell lysate.

In another example, we compared miR-ID and TaqMan assays for relative quantification of five miRNAs (let-7a, miR-16, miR-20, miR-21, and miR-22). The two types of assays were performed side-by-side using samples of total

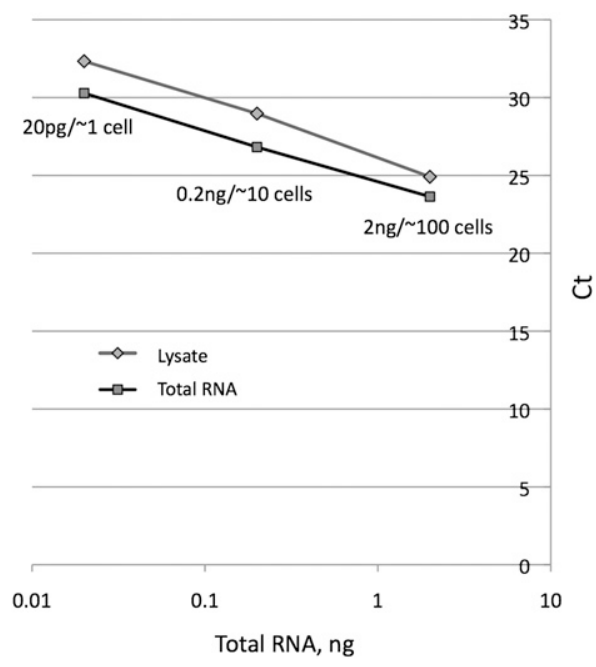

FIGURE 10. Side-by-side comparison of let-7b detection from purified total RNA versus whole-cell lysates. Standard curves were generated for a dilution series from $20 \mathrm{ng}$ to $20 \mathrm{pg}$ of total RNA (squares) extracted from Jurkat cells or corresponding amounts of lysate (diamonds) of these cells.
RNA extracted from various mouse tissues (Table 2). For miR-ID, the RTC step (Fig. 1B) was performed in multiplex format using all five RT primers simultaneously (see sequences in Table 1), whereas for the TaqMan assays, this step employed the obligatory singleplex RT reactions as previously described by Chen et al. (2005). sno-234 RNA was used as an endogenous reference control (for normalizing input RNA) in both methods. The miRNA expression levels relative to liver determined by these two methods were found to be in good correlation $(R=0.92)$. Similar levels of agreement in relative miRNA expression levels determined by different methods have been seen in other comparative studies (Nelson et al. 2008; Linsen et al. 2009; Git et al. 2010). The performance of each method depends on the miRNA being assayed and, to some extent, on the tissue of origin. Dependence on the target miRNA can be explained by differences in the relative efficiency of primer binding (primer bias) and of enzymatic action (enzymatic bias) for each target sequence. Dependence on tissue may arise because the different populations of miRNAs present in different tissues represent different sets of off-targets, and their influence depends on the sequence specificity of the platform. Because different assays use different primers and different enzymatic steps, each of these sources of bias is assay-dependent. No single method can give accurate values of absolute copy numbers for different miRNAs present in a sample without generation of standard dilution curves for each miRNA and for each type of biological sample.

\section{Differentiation between $2^{\prime}-\mathrm{OH}$ and 2'-OMe ending miRNAs}

While all miRNAs found in vertebrates have 2 '-OH groups at their $3^{\prime}$-terminal nucleotides, many other small RNAs have a $2^{\prime}$-OMe modification at this residue $\left(2^{\prime}\right.$-OMe RNAs), including miRNAs from plants (Yu et al. 2005), miRNAs and piRNAs from Drosophila (Horwich et al. 2007; Czech et al. 2009), and mammalian piRNAs (Kirino and Mourelatos 2007; Ohara et al. 2007). Other than miRID, none of the currently available RT-PCR assays can differentiate between unmodified and the 2'-OMe RNAs. The ability of miR-ID to detect and differentiate these classes of RNAs is based on the distinct substrate requirements of the ligases discussed in this study: both Rnl1 and CLII can circularize the $2^{\prime}-\mathrm{OH}$ forms (Fig. 2), while only CLII can circularize 2'-OMe RNAs (Fig. 3). Since circularization is an absolute requirement for the assay, either ligase will provide detection of $2^{\prime}-\mathrm{OH}$ miRNAs, but only CLII allows detection of 2'-OMe miRNAs. By comparing results of miR-ID assays that use each ligase in separate circularization reactions, it is possible to differentiate these two forms of small RNAs.

As an example, we demonstrated the ability of miR-ID to determine the relative proportions of $2^{\prime}-\mathrm{OH}$ and $2^{\prime}-\mathrm{OMe}$ 
TABLE 2. Relative expression levels of selected endogenous miRNAs in various mouse tissues determined by miR-ID (ID) and TaqMan (TM) assays

\begin{tabular}{|c|c|c|c|c|c|c|c|c|c|c|c|c|c|c|}
\hline \multirow{2}{*}{$\frac{\text { Tissue }}{\text { miRNA }}$} & \multicolumn{2}{|c|}{ Brain } & \multicolumn{2}{|c|}{ Heart } & \multicolumn{2}{|c|}{ Liver } & \multicolumn{2}{|c|}{ Lung } & \multicolumn{2}{|c|}{ Thymus } & \multicolumn{2}{|c|}{ Ovary } & \multicolumn{2}{|c|}{ Embryo } \\
\hline & ID & TM & ID & TM & ID & $\mathrm{TM}$ & ID & TM & ID & TM & ID & TM & ID & TM \\
\hline a & 3.4 & 3.7 & 3.3 & 4.9 & 1.0 & 1.0 & 3.1 & 4.9 & 1.1 & 1.9 & 1.1 & 1.6 & 2.0 & 4.0 \\
\hline miR-16 & 1.7 & 2.8 & 6.9 & 5.4 & 1.0 & 1.0 & 6.5 & 6.6 & 4.3 & 7.3 & 1.0 & 1.0 & 1.3 & 3.4 \\
\hline miR-20 & 0.3 & 0.5 & 2.7 & 2.9 & 1.0 & 1.0 & 6.0 & 7.2 & 11.4 & 16.3 & 2.8 & 2.4 & 9.6 & 9.7 \\
\hline miR-21 & 0.1 & 0.25 & 0.8 & 1.5 & 1.0 & 1.0 & 1.3 & 2.6 & 0.2 & 0.6 & 0.4 & 0.4 & 0.2 & 0.2 \\
\hline miR-22 & 0.8 & 0.9 & 5.4 & 5.8 & 1.0 & 1.0 & 1.9 & 2.0 & 0.1 & 0.25 & 0.4 & 0.4 & 0.2 & 0.6 \\
\hline
\end{tabular}

Each RT and qPCR reaction was carried out in duplicate. The average expression levels (from four measurements) of the miRNAs were determined for both methods $(R=0.92)$ and normalized to liver expression levels.
RNAs in various mixtures of the two. For this purpose, synthetic let-7b miRNAs having $5^{\prime}-\mathrm{p}$ and either $2^{\prime}-\mathrm{OH} /$ $3^{\prime}-\mathrm{OH}$ or $2^{\prime}-\mathrm{OMe} / 3^{\prime}-\mathrm{OH}$ at their $3^{\prime}$-ends were mixed in five preset proportions (from $0 \%$ to $100 \% 2^{\prime}-\mathrm{OMe}$ ), keeping the total RNA concentration constant. Identical samples of these mixtures were circularized using either Rnll or CLII, followed by identical RTC and qPCR procedures. The resulting $C t$ values were converted into linear percentage values and plotted as shown in Figure 11A. As expected, CLII provided indiscriminate detection of both $2^{\prime}-\mathrm{OH}$ and $2^{\prime}$-OMe forms, while Rnll detected only the $2^{\prime}-\mathrm{OH}$ miRNAs. Normalizing the CLII results to 100 gave the percentage of 2'-OH RNA in the mixture. Good correlation between the preset and experimentally determined ratios confirms the ability of miR-ID to accurately identify each form of miRNA in a mixture.

To test this capability of miR-ID on endogenous miRNAs, we assayed miR-162a and miR-775 miRNAs from the Arabidopsis thaliana wild type, in which all miRNAs exist primarily in the 2'-OMe form, and an Hen1-1 mutant, in which the activity of the HEN1 protein responsible for the 2 '-OMe modification was attenuated, resulting in a population of miRNAs with $2^{\prime}-\mathrm{OH}$ at their $3^{\prime}$-ends ( $\mathrm{Li}$ et al. 2005). The differences between Rnl1- and CLII-based miRID assays (Fig. 11B) indicate that most of the two miRNAs assayed are in the $2^{\prime}$-OMe form in the wild type and the $2^{\prime}$-OH form in the Hen1-1 mutant, as expected. A similar approach was used to confirm the methylation status of the piRNA piR-1 from mouse testis (Kirino and Mourelatos 2007; data not shown).

miR-ID is an attractive alternative to the commonly used periodate-oxidation method for identifying 2'-O-methylation at the $3^{\prime}$-end of small RNAs (Yang et al. 2007). That method has several disadvantages: (1) It is laborious; (2) it requires gel-electrophoresis analysis, which offers comparatively low sensitivity and is semi-quantitative; and (3) it is not specific to individual miRNAs. In contrast, miR-ID is quantitative, sequence-specific, and highly sensitive.

miR-ID can also be used to detect and differentiate small RNAs that have naturally occurring nonligatable ends, such as triphosphate (ppp) (Pak and Fire 2007), or cap ( $\left.\mathrm{m}^{7} \mathrm{Gppp}\right)$ structures at the $5^{\prime}$-end (Shimba et al. 1992), or phosphate groups at the $3^{\prime}$-end (cyclic $2^{\prime}, 3^{\prime}-$ p or $\left.2^{\prime}-\mathrm{p} / 3^{\prime}-\mathrm{p}\right)$ (Schutz et al. 2010). The need for a specific enzymatic treatment that could convert these ends into ligatable forms prior to the circularization step for detection of certain small RNAs by miR-ID would indicate the presence of the corresponding modifications at their ends. Such end-specific enzymes include $5^{\prime}$-polyphosphatase $\left(5^{\prime}\right.$-ppp $\left.\rightarrow 5^{\prime}-\mathrm{p}\right)$, tobacco acid pyrophosphatase $\left(5^{\prime}-\mathrm{m}^{7} \mathrm{Gppp} \rightarrow 5^{\prime}-\mathrm{p}\right)$, and T4 polynucleotide kinase $\left(2^{\prime}, 3^{\prime}-\mathrm{p} \rightarrow 2^{\prime}, 3^{\prime}-\mathrm{OH}\right.$ and $5^{\prime}-\mathrm{OH}$ $\rightarrow 5^{\prime}$-p) (Epicentre Biotechnologies 2010). Since the treated small RNAs will have $5^{\prime}$-p and $2^{\prime}-\mathrm{OH} / 3^{\prime}-\mathrm{OH}$ ends, either Rnll or CLII can be use for circularization.

In summary, the miR-ID assay showed superior performance compared to the currently available PCR-based methods for miRNA detection, including the current "gold standard," the TaqMan microRNA assay. The method provides robust quantification of endogenous miRNAs in total RNA as well as directly in cell lysates, even in amounts corresponding to a single cell. The ability to identify $2^{\prime}$ OMe RNAs and differentiate them from the $2^{\prime}-\mathrm{OH}$ forms provides a new tool for studies of small RNAs. These capabilities, together with the cost advantages of dispensing with modified probes (e.g., TaqMan) and primers (e.g., LNA), could help make studies of small RNAs attractive to a wider community of researchers. In the course of this work, several new findings of general interest have emerged, including the effects of $3^{\prime}$-end nucleotides on circularization of small RNAs, the reverse transcription of small RNA circles, and the use of $5^{\prime}$-overlapping primers for detection of repetitive sequences by qPCR.

\section{MATERIALS AND METHODS}

All synthetic RNAs, RT and qPCR DNA primers were obtained from IDT. Sequences are provided in Table 1.

\section{Mature and precursor miRNA}

Synthetic mature miRNAs contained either $5^{\prime}-\mathrm{OH}$ or 5 -p at their $5^{\prime}$-end, and either $2^{\prime}-\mathrm{OH} / 3^{\prime}-\mathrm{OH}$ or $2^{\prime}-\mathrm{OMe} / 3^{\prime}-\mathrm{OH}$ at their $3^{\prime}$-end. Synthetic miRNAs having $5^{\prime}-\mathrm{OH}$ were ${ }^{32} \mathrm{P}$-phosphorylated at their $5^{\prime}$-ends using polynucleotide kinase (NEB) following the manufacturer's instructions. Synthetic pre-let-7b was obtained by annealing the synthetic RNAs ( $5^{\prime}$-pUGAGGUAGUAGGUUGU GUGGUUUCAGGGCAGUGAUGU) and (5' AGAUAACUAUACAACCUACUGCCUUCC) and then ligating the $3^{\prime}$-end of the first RNA with the $5^{\prime}$-end of the second RNA using $0.67 \mathrm{U} / \mu \mathrm{L}$ Rnl 1 for $16 \mathrm{~h}$ at $16^{\circ} \mathrm{C}$ in the standard ligation buffer (10 $\mathrm{mM} \mathrm{MgCl}_{2}, 10 \mathrm{mM} \mathrm{DTT}, 50 \mathrm{mM}$ Tris- $\mathrm{HCl}$ at $\mathrm{pH}$ 7.8). 

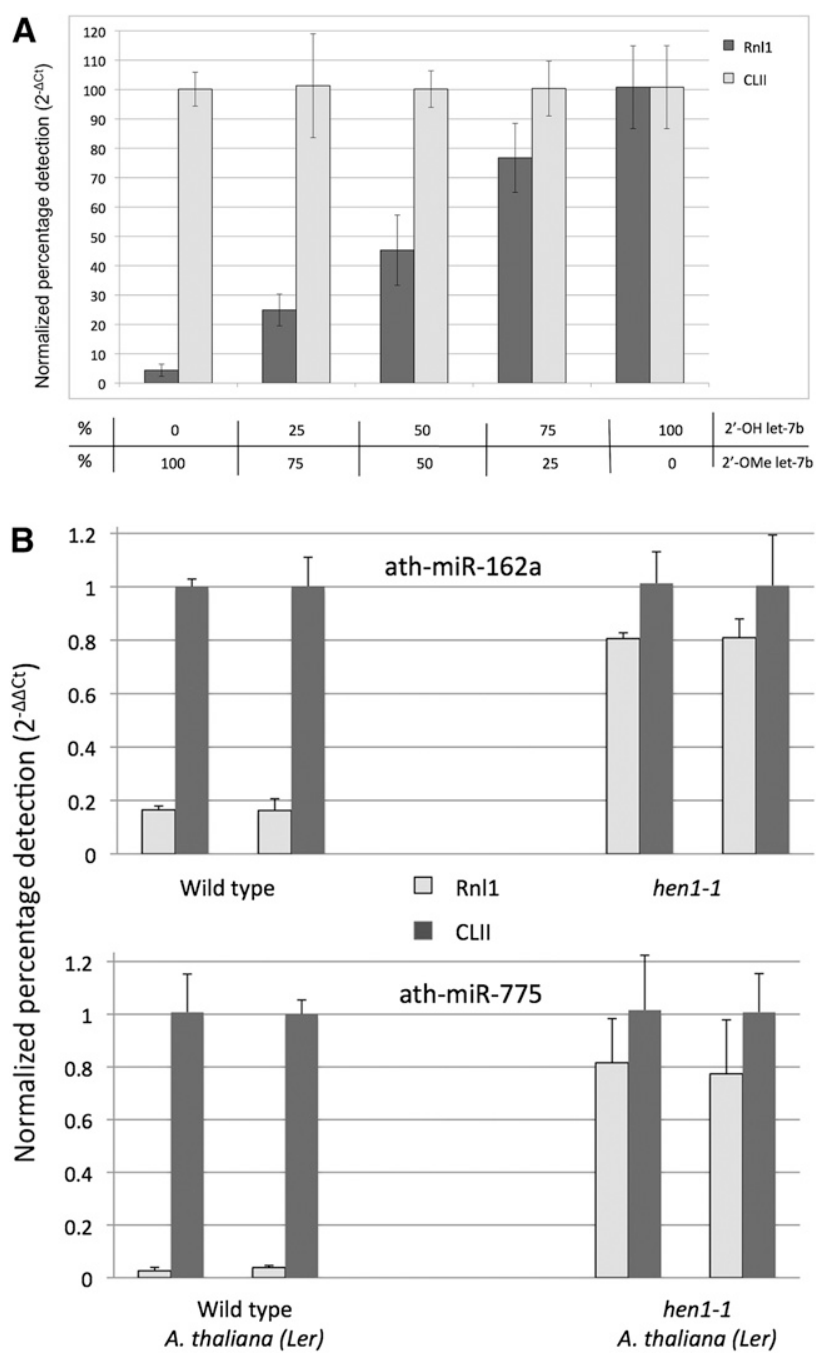

FIGURE 11. Determination of $2^{\prime}$-O-methylation status of miRNAs using miR-ID. (A) Quantification of $2^{\prime}$-OMe and $2^{\prime}-\mathrm{OH}$ forms of the same miRNA in a mixture. Synthetic let-7b miRNAs having $5^{\prime}$-p and either $2^{\prime}-\mathrm{OH} / 3^{\prime}-\mathrm{OH}$ or $2^{\prime}-\mathrm{OMe} / 3^{\prime}-\mathrm{OH}$ at their $3^{\prime}$-ends were used in this example. These miRNAs were mixed in five predefined proportions, with the total concentration of let-7b RNA constant at 20 pM. Each mixture was subjected to an miR-ID assay in which either Rnl1 or CLII was used in the circularization step, followed by the usual RTC and qPCR steps. For each assay, the $C t$ value was normalized and converted into a linear percentage, with the CLII assay results made equal to $100 \%$. The Rnl1-based assay gives the concentration of $2^{\prime}-\mathrm{OH}$ form in the mixture, and normalization to the CLII- based results gives the relative percentage of the $2^{\prime}-\mathrm{OH}$ and $2^{\prime}$-OMe forms. (B) Identification of plant miRNAs having $2^{\prime}$-OMe or $2^{\prime}-\mathrm{OH}$ at their $3^{\prime}$-ends. miR-162a and miR-775 miRNAs were assayed in total RNA extracted from wild-type Arabidopsis thaliana plants (Ler) and hen1-1 mutants (Ler). In the wild type, all miRNAs have a $2^{\prime}$-OMe group at the $3^{\prime}$-end, whereas in the mutant, miRNAs are expected to be unmethylated. One hundred nanogram samples of total RNA were subjected to miR-ID assays in which either Rnll or CLII was used in the circularization step, followed by the usual RTC and $\mathrm{qPCR}$ steps. The $C t$ values obtained for the CLII-based assays were normalized to 1.00 , and the relative signals obtained for Rnl1based assays were calculated. Two biological replicates for both plant types represented by the gray and black columns are shown.
The ligation products were analyzed on a denaturing $15 \%$ polyacrylamide gel, and full-length pre-let-7b was gel-purified.

\section{Cell lysate preparation and RNA extraction}

Total RNA from brain, heart, liver, thymus, lung, embryo, ovary (AM7800), and testis (AM7822) of mouse was purchased from Ambion. Total RNA from Jurkat cells and wild-type A. thaliana plants (Ler) and hen1-1 mutants was isolated using a Trizol kit (Invitrogen/Life Technologies) according to the manufacturer's instructions. Cell lysates from Jurkat cells were prepared using the nucleic acid purification lysis solution from Life Technologies (Cat. No. 4305895) according to the manufacturer's instructions.

\section{Circularization (miR-ID Step 1)}

Rnl1

Samples were subjected to circularization by $0.67 \mathrm{U} / \mu \mathrm{L}$ Rnl1 (NEB), incubated for $1 \mathrm{~h}$ at $37^{\circ} \mathrm{C}$ in the recommended buffer $(10$ $\mathrm{mM} \mathrm{MgCl}_{2}, 1 \mathrm{mM}$ ATP, $10 \mathrm{mM}$ DTT, $50 \mathrm{mM}$ Tris- $\mathrm{HCl}$ at $\mathrm{pH} 7.8$ ) in a $20-\mu \mathrm{L}$ reaction volume.

\section{CLII}

Samples were subjected to circularization by $5 \mathrm{U} / \mu \mathrm{L}$ CLII, incubated for $1 \mathrm{~h}$ at $60^{\circ} \mathrm{C}$ in the recommended buffer $(66 \mathrm{mM}$ $\mathrm{KCl}, 0.5 \mathrm{mM}$ DTT, $2.5 \mathrm{mM} \mathrm{MnCl}_{2}, 1 \mathrm{M}$ betaine, $33 \mathrm{mM}$ TrisAcetate at $\mathrm{pH} 7.8$ ) in a $20-\mu \mathrm{L}$ reaction volume.

\section{Reverse transcription (miR-ID Step 2)}

A $50-\mu \mathrm{L}$ reverse transcription reaction was set up containing circularized RNA as template (one-tenth of the volume of the circularization reaction), specific RT primers (in multiplex or singleplex) at a concentration of $100 \mathrm{nM}$ each (unless otherwise indicated in a figure legend), $0.4 \mathrm{mM}$ dNTPs, $10 \mathrm{mM}$ DTT, 0.4 $\mathrm{U} / \mu \mathrm{L}$ RNAseOUT ribonuclease inhibitor, and $4 \mathrm{U} / \mu \mathrm{L}$ SuperScript II Reverse Transcriptase (Invitrogen) in the recommended buffer conditions (10 mM DTT, $0.4 \mathrm{mM}$ dNTPs, $75 \mathrm{mM} \mathrm{KCl,} 3 \mathrm{mM}$ $\mathrm{MgCl}_{2}, 50 \mathrm{mM}$ Tris- $\mathrm{HCl}$ at $\mathrm{pH} 8.3$ ). The reaction was incubated for $2 \mathrm{~h}$ at $42^{\circ} \mathrm{C}$, followed by $15 \mathrm{~min}$ at $75^{\circ} \mathrm{C}$ to inactivate the enzyme.

\section{qPCR (miR-ID Step 3)}

After circularization and reverse transcription (as described in Steps 1 and 2 above), the cDNA was used as template for qPCR amplification using specific $5^{\prime}$-overlapping primers (Table 1) in singleplex reactions. A $20-\mu \mathrm{L}$ reaction was set up containing $2 \mu \mathrm{L}$

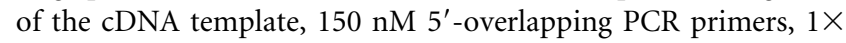
Brilliant II SYBR Green QPCR master mix (Stratagene, Cat. No. 600828), and $375 \mathrm{nM}$ Reference dye (Stratagene, Cat. No. 600828). The $\mathrm{qPCR}$ reaction involved $2 \mathrm{~min}$ at $50^{\circ} \mathrm{C}$, then 10 min at $95^{\circ} \mathrm{C}$, followed by 45 cycles of $\left(95^{\circ} \mathrm{C}\right.$ for $45 \mathrm{sec} / 56^{\circ} \mathrm{C}$ for 45 sec $/ 66^{\circ} \mathrm{C}$ for $30 \mathrm{sec} / 67^{\circ} \mathrm{C}$ for $\left.30 \mathrm{sec}\right)$. The $66^{\circ} \mathrm{C}$ step was increased by $0.1^{\circ} \mathrm{C}$ each cycle and the $67^{\circ} \mathrm{C}$ step by $+0.2^{\circ} \mathrm{C}$ per cycle. Data were collected at the final extension step of each cycle. A melting curve was also plotted to validate the presence of a single dominant amplification product. The qPCR was performed on an Applied Biosystems 7500-fast system. All qPCR reactions were done in triplicate. $C t$ values were exported and analyzed using Microsoft Excel 2008. 


\section{Characterization of miR-ID PCR products}

After circularization and reverse transcription as described above, the resulting cDNA was used as the template for PCR amplification using $5^{\prime}$-overlapping primers. One-tenth volume of the samples from the RT reaction was mixed with $400 \mathrm{nM}$ primers and $0.1 \mathrm{U} / \mu \mathrm{L}$ Hot FirePol DNA Polymerase (Solis BioDyne) in the supplied buffer. These PCR reaction mixtures were subjected to initial denaturation for $15 \mathrm{~min}$ at $94^{\circ} \mathrm{C}$ (to activate the enzyme), followed by 20 or 25 cycles of PCR: $94^{\circ} \mathrm{C}$ for $45 \mathrm{sec} / 58^{\circ} \mathrm{C}$ for $45 \mathrm{sec} / 70^{\circ} \mathrm{C}$ for $30 \mathrm{sec}$. The PCR products were analyzed on a $3 \%$ agarose gel and stained by ethidium bromide.

\section{TaqMan assay}

\section{Standard curve generation for cel-lin-4}

Various concentrations of synthetic lin- 4 were subjected to RT and qPCR using a lin-4-specific RT and PCR primer-probe kit (AB Assay ID: 000258) as described (AB/Life Technologies, Cat. No. 4366596). Real-time qPCR was performed on the ABI 7500fast system according to the recommended cycling conditions. All qPCR reactions were done in triplicate. $C t$ values were obtained and analyzed using Microsoft Excel 2008.

\section{MiRNA profiling of mouse tissue}

One hundred nanograms of mouse total RNA from brain, heart, liver, thymus, lung, embryo, and ovary (AB Cat. No. AM7800) was subjected to RT and qPCR using individual RT and PCR primer probes specific for let-7a ( $\mathrm{AB}$ Kit 4373169), miR-16 (AB Kit 4373121), miR-20 (AB Kit 4373286), miR-21 (AB Kit 4373090), miR-22 (AB Kit 4373079), and sno234 (AB Kit 4380915) as described (AB/Life Technologies, Cat. No. 4366596). Ct values were obtained and analyzed using Microsoft Excel 2008.

\section{ACKNOWLEDGMENTS}

We thank TransDerm, Inc. for access to equipment; Heini Ilves (Somagenics) for providing total RNA and cell lysates from Jurkat cells; Joshua Shorenstein (Somagenics) for technical assistance; Dr. Daniela Pignatta (UC Berkeley) for providing total RNA from A. thaliana plants; and Dr. Sumedha Jayasena for comments. This work was supported in part by NIH grant 1R43CA134277 to S.A.K.

Received October 11, 2010; accepted November 10, 2010.

\section{REFERENCES}

ABI. 2010. Protocol: TaqMan microRNA assays. http://www3. appliedbiosystems.com/cms/groups/mcb_support/documents/ generaldocuments/cms_042167.pdf.

Allawi HT, Dahlberg JE, Olson S, Lund E, Olson M, Ma WP, Takova T, Neri BP, Lyamichev VI. 2004. Quantitation of microRNAs using a modified invader assay. RNA 10: 1153-1161.

Ambion 2008. mirVana miRNA Reference Panel v9.1. User information: Real-Time RT-PCR: Using TaqMan microRNA assays. http://tools.invitrogen.com/content/sfs/manuals/sp_4388891.pdf.

Aravin A, Tuschl T. 2005. Identification and characterization of small RNAs involved in RNA silencing. FEBS Lett 579: 5830-5840.
Baker M. 2010. MicroRNA profiling: separating signal from noise. Nat Methods 7: 687-692.

Barrio JR, Barrio MC, Leonard NJ, England TE, Uhlenbeck OC. 1978. Synthesis of modified nucleoside $3^{\prime}, 5^{\prime}$-bisphosphates and their incorporation into oligoribonucleotides with T4 RNA ligase. Biochemistry 17: 2077-2081.

Ben-Artzi H, Zeelon E, Amit B, Wortzel A, Gorecki M, Panet A. 1993. RNase $\mathrm{H}$ activity of reverse transcriptases on substrates derived from the $5^{\prime}$ end of retroviral genome. J Biol Chem 268: 1646516471.

Benes V, Castoldi M. 2010. Expression profiling of microRNA using real-time quantitative PCR, how to use it and what is available. Methods 50: 244-249.

Blondal T, Hjorleifsdottir SH, Fridjonsson OF, Aevarsson A, Skirnisdottir S, Hermannsdottir AG, Hreggvidsson GO, Smith AV, Kristjansson JK. 2003. Discovery and characterization of a thermostable bacteriophage RNA ligase homologous to T4 RNA ligase 1. Nucleic Acids Res 31: 7247-7254.

Bracho MA, García-Robles I, Jiménez N, Torres-Puente M, Moya A, González-Candelas F. 2004. Effect of oligonucleotide primers in determining viral variability within hosts. Virol $J$ 1: 13. doi: 10.1186/1743-422X-1-13.

Bushati N, Cohen SM. 2007. MicroRNA functions. Annu Rev Cell Dev Biol 23: 175-205.

Chen C, Ridzon DA, Broomer AJ, Zhou Z, Lee DH, Nguyen JT, Barbisin M, Xu NL, Mahuvakar VR, Andersen MR, et al. 2005. Real-time quantification of microRNAs by stem-loop RT-PCR. Nucleic Acids Res 33: e179. doi: 10.1093/nar/gni178.

Cheng Y, Zhang X, Li Z, Jiao X, Wang Y, Zhang Y. 2009. Highly sensitive determination of microRNA using target-primed and branched rolling-circle amplification. Angew Chem Int Ed Engl 48: 3268-3272.

Cranston JW, Silber R, Malathi VG, Hurwitz J. 1974. Studies on ribonucleic acid ligase. Characterization of an adenosine triphosphateinorganic pyrophosphate exchange reaction and demonstration of an enzyme-adenylate complex with T4 bacteriophage-induced enzyme. J Biol Chem 249: 7447-7456.

Czech B, Zhou R, Erlich Y, Brennecke J, Binari R, Villalta C, Gordon A, Perrimon N, Hannon GJ. 2009. Hierarchical rules for Argonaute loading in Drosophila. Mol Cell 36: 445-456.

Demidov VV. 2002. Rolling-circle amplification in DNA diagnostics: the power of simplicity. Expert Rev Mol Diagn 2: 542-548.

Ebhardt HA, Thi EP, Wang MB, Unrau PJ. 2005. Extensive 3' modification of plant small RNAs is modulated by helper component-proteinase expression. Proc Natl Acad Sci 102: 13398-13403.

England TE, Uhlenbeck OC. 1978. Enzymatic oligoribonucleotide synthesis with T4 RNA ligase. Biochemistry 17: 2069-2076.

Epicentre Biotechnologies 2010. ExactSTART platform of transcriptome discovery and analysis tools. http://www.epibio.com/exactstart/ exactstart.asp.

Fire A, Xu SQ. 1995. Rolling replication of short DNA circles. Proc Natl Acad Sci 92: 4641-4645.

Frieden M, Pedroso E, Kool ET. 1999. Tightening the belt on polymerases: evaluating the physical constraints on enzyme substrate size. Angew Chem Int Ed Engl 38: 3654-3657.

Fu HJ, Zhu J, Yang M, Zhang ZY, Tie Y, Jiang H, Sun ZX, Zheng XF. 2006. A novel method to monitor the expression of microRNAs. Mol Biotechnol 32: 197-204.

Git A, Dvinge H, Salmon-Divon M, Osborne M, Kutter C, Hadfield J, Bertone P, Caldas C. 2010. Systematic comparison of microarray profiling, real-time PCR, and next-generation sequencing technologies for measuring differential microRNA expression. RNA 16: 991-1006.

Griffiths-Jones S. 2010. miRBase: microRNA sequences and annotation. Curr Protoc Bioinformatics 12: Unit 12.9.1-Unit 12.9.10.

Harrison B, Zimmerman SB. 1984. Polymer-stimulated ligation: enhanced ligation of oligo- and polynucleotides by T4 RNA ligase in polymer solutions. Nucleic Acids Res 12: 8235-8251. 
Hartig JS, Grune I, Najafi-Shoushtari SH, Famulok M. 2004. Sequencespecific detection of microRNAs by signal amplifying ribozymes. J Am Chem Soc 126: 722-723.

Hemat F, McEntee K. 1994. A rapid and efficient PCR-based method for synthesizing high-molecular-weight multimers of oligonucleotides. Biochem Biophys Res Commun 205: 475-481.

Ho CK, Shuman S. 2002. Bacteriophage T4 RNA ligase 2 (gp24.1) exemplifies a family of RNA ligases found in all phylogenetic domains. Proc Natl Acad Sci 99: 12709-12714.

Horwich MD, Li C, Matranga C, Vagin V, Farley G, Wang P, Zamore PD. 2007. The Drosophila RNA methyltransferase, DmHen1, modifies germline piRNAs and single-stranded siRNAs in RISC. Curr Biol 17: 1265-1272.

Jonstrup SP, Koch J, Kjems J. 2006. A. microRNA detection system based on padlock probes and rolling circle amplification. RNA 12: 1747-1752.

Kaufmann G, Klein T, Littauer UZ. 1974. T4 RNA ligase: substrate chain length requirements. FEBS Lett 46: 271-275.

Kirino Y, Mourelatos Z. 2007. Mouse Piwi-interacting RNAs are 2'$O$-methylated at their $3^{\prime}$ termini. Nat Struct Mol Biol 14: 347-348.

Kong D, Shen H, Huang Y, Mi H. 2004. PCR hot-start using duplex primers. Biotechnol Lett 26: 277-280.

Lao K, Xu NL, Yeung V, Chen C, Livak KJ, Straus NA. 2006. Multiplexing RT-PCR for the detection of multiple miRNA species in small samples. Biochem Biophys Res Commun 343: 85-89.

Lee EJ, Baek M, Gusev Y, Brackett DJ, Nuovo GJ, Schmittgen TD. 2008. Systematic evaluation of microRNA processing patterns in tissues, cell lines, and tumors. RNA 14: 35-42.

Li Q, Luan G, Guo Q, Liang J. 2002. A new class of homogeneous nucleic acid probes based on specific displacement hybridization. Nucleic Acids Res 30: e5. doi: 10.1093/nar/30.2.e5

Li J, Yang Z, Yu B, Liu J, Chen X. 2005. Methylation protects miRNAs and siRNAs from a $3^{\prime}$-end uridylation activity in Arabidopsis. Curr Biol 15: 1501-1507.

Linsen SE, de Wit E, Janssens G, Heater S, Chapman L, Parkin RK, Fritz B, Wyman SK, de Bruijn E, Voest EE, et al. 2009. Limitations and possibilities of small RNA digital gene expression profiling. Nat Methods 6: 474-476.

Liu D, Daubendiek SL, Zillman MA, Ryan K, Kool ET. 1996. Rolling circle DNA synthesis: small circular oligonucleotides as efficient templates for DNA polymerases. J Am Chem Soc 118: 15871594.

Mitchell PS, Parkin RK, Kroh EM, Fritz BR, Wyman SK, PogosovaAgadjanyan EL, Peterson A, Noteboom J, O'Briant KC, Allen A, et al. 2008. Circulating microRNAs as stable blood-based markers for cancer detection. Proc Natl Acad Sci 105: 10513-10518.

Nelson PT, Wang WX, Wilfred BR, Tang G. 2008. Technical variables in high-throughput miRNA expression profiling: Much work remains to be done. Biochim Biophys Acta 1779: 758-765.

Ohara T, Sakaguchi Y, Suzuki T, Ueda H, Miyauchi K, Suzuki T. 2007. The $3^{\prime}$ termini of mouse Piwi-interacting RNAs are 2'-O-methylated. Nat Struct Mol Biol 14: 349-350.

O'Hara AJ, Chugh P, Wang L, Netto EM, Luz E, Harrington WJ, Dezube BJ, Damania B, Dittmer DP. 2009. Pre-micro RNA signatures delineate stages of endothelial cell transformation in Kaposi sarcoma. PLoS Pathog 5: e1000389. doi: 10.1371/journal. ppat.1000389.

Ohtsuka E, Doi T, Uemura H, Taniyama Y, Ikehara M. 1980. Comparison of substrate base sequences for RNA ligase reactions in the synthesis of a tetradecanucleotide corresponding to bases 21-34 of E. coli RRNA $_{\mathrm{f}}^{\text {Met } 1}$. Nucleic Acids Res 8: 3909-3916.

Pak J, Fire A. 2007. Distinct populations of primary and secondary effectors during RNAi in C. elegans. Science 315: 241-244.

Qiagen. 2009. microRNA sample and assay technologies. http://www. qiagen.com/literature/brochures/category.aspx?ID=9073.

Raymond CK, Roberts BS, Garrett-Engele P, Lim LP, Johnson JM. 2005. Simple, quantitative primer-extension PCR assay for direct monitoring of microRNAs and short-interfering RNAs. RNA 11: $1737-1744$.
Reichenstein I, Aizenberg N, Goshen M, Bentwich Z, Avni YS. 2010. A novel qPCR assay for viral encoded microRNAs. J Virol Methods 163: 323-328.

Ro S, Park C, Jin J, Sanders KM, Yan W. 2006. A PCR-based method for detection and quantification of small RNAs. Biochem Biophys Res Commun 351: 756-763.

Romaniuk E, McLaughlin LW, Neilson T, Romaniuk PJ. 1982. The effect of acceptor oligoribonucleotide sequence on the T4 RNA ligase reaction. Eur J Biochem 125: 639-643.

Schmittgen TD, Jiang J, Liu Q, Yang L. 2004. A high-throughput method to monitor the expression of microRNAs precursor. Nucleic Acids Res 32: 43-53.

Schutz K, Hesselberth JR, Fields S. 2010. Capture and sequence analysis of RNAs with terminal $2^{\prime}, 3^{\prime}$-cyclic phosphates. RNA 16: 621-631.

Sharbati-Tehrani S, Kutz-Lohroff B, Bergbauer R, Scholven J, Einspanier R. 2008. miR-Q: a novel quantitative RT-PCR approach for the expression profiling of small RNA molecules such as miRNAs in a complex sample. BMC Mol Biol 9: 34. doi: 10.1186/1471-21999-34.

Shi R, Chiang VL. 2005. Facile means for quantifying microRNA expression by real-time PCR. Biotechniques 39: 519-525.

Shimba S, Buckley B, Reddy R, Kiss T, Filipowicz W. 1992. Cap structure of U3 small nucleolar RNA in animal and plant cells is different. $\gamma$-Monomethyl phosphate cap structure in plant RNA. J Biol Chem 267: 13772-13777.

Silber R, Malathi VG, Hurwitz J. 1972. Purification and properties of bacteriophage T4-induced RNA ligase. Proc Natl Acad Sci 69: 3009-3013.

Silverman SK. 2004. Practical and general synthesis of $5^{\prime}$-adenylated RNA (5'-AppRNA). RNA 10: 731-746.

Siva AC, Nelson LJ, Fleischer CL, Majlessi M, Becker MM, Vessella RL, Reynolds MA. 2009. Molecular assays for the detection of microRNAs in prostate cancer. Mol Cancer 8: 17. doi: 10.1186/ 1476-4598-8-17.

Uhlenbeck OC, Gumport RI. 1982. T4 RNA ligase. Enzymes (Essen) 15: $31-58$.

Vallejo AN, Pogulis RJ, Pease LR. 1994. In vitro synthesis of novel genes: mutagenesis and recombination by PCR. PCR Methods Appl 4: S123-S130.

van Huffel C, Remacle J, Buelow S, Zammatteo N. 2006. Method for the determination of cellular regulation by microRNAs. US Patent Application US2006134639.

Varkonyi-Gasic E, Hellens RP. 2010. qRT-PCR of small RNAs. Methods Mol Biol 631: 109-122.

Wan G, Lim QE, Too HP. 2010. High-performance quantification of mature microRNAs by real-time RT-PCR using deoxyuridineincorporated oligonucleotides and hemi-nested primers. RNA 16: $1436-1445$.

Wang X. 2009. A PCR-based platform for microRNA expression profiling studies. RNA 15: 716-723.

Wang L, Ruffner DE. 1998. Oligoribonucleotide circularization by 'template-mediated' ligation with T4 RNA ligase: synthesis of circular hammerhead ribozymes. Nucleic Acids Res 26: 2502-2504.

Wang LK, Ho CK, Pei Y, Shuman S. 2003. Mutational analysis of bacteriophage T4 RNA ligase 1. Different functional groups are required for the nucleotidyl transfer and phosphodiester bond formation steps of the ligation reaction. J Biol Chem 278: 2945429462.

Wang Y, Kim D, Gibbons J, Zeng X, Pang L, Quellhorst G. 2009. RT miRNA PCR arrays. The complete system for genome-wide and pathway focused microRNAs. http://www.gene-quantification.de/ sabiosciences-microRNA-arrays-white-paper.pdf.

White MJ, Fristensky BW, Thompson WF. 1991. Concatamer chain reaction: a Taq DNA polymerase-mediated mechanism for generating long tandemly repetitive DNA sequences. Anal Biochem 199: 184-190.

Yang Z, Ebright YW, Yu B, Chen X. 2006. HEN1 recognizes 21-24 nt small RNA duplexes and deposits a methyl group onto the 


\section{Kumar et al.}

$2^{\prime} \mathrm{OH}$ of the $3^{\prime}$ terminal nucleotide. Nucleic Acids Res 34: 667675.

Yang Z, Vilkaitis G, Yu B, Klimasauskas S, Chen X. 2007. Approaches for studying microRNA and small interfering RNA methylation in vitro and in vivo. Methods Enzymol 427: 139-154.

Yang H, Schmuke JJ, Flagg LM, Roberts JK, Allen EM, Ivashuta S, Gilbertson LA, Armstrong TA, Christian AT. 2009. A novel real-time polymerase chain reaction method for high throughput quantification of small regulatory RNAs. Plant Biotechnol J 7: 621-630.

Yao B, Li J, Huang H, Sun C, Wang Z, Fan Y, Chang Q, Li S, Xi J. 2009. Quantitative analysis of zeptomole microRNAs based on isothermal ramification amplification. RNA 15: 1787-1794.

Yu B, Yang Z, Li J, Minakhina S, Yang M, Padgett RW, Steward R, Chen X. 2005. Methylation as a crucial step in plant microRNA biogenesis. Science 307: 932-935.
Yu J, Wang F, Yang GH, Wang FL, Ma YN, Du ZW, Zhang JW. 2006. Human microRNA clusters: genomic organization and expression profile in leukemia cell lines. Biochem Biophys Res Commun 349: 59-68.

Zamore PD, Haley B. 2005. Ribo-gnome: The big world of small RNAs. Science 309: 1519-1524.

Zhang B, Farwell MA. 2008. MicroRNAs: a new emerging class of players for disease diagnostics and gene therapy. J Cell Mol Med 12: 3-21.

Zhang DY, Brandwein M, Hsuih TC, Li H. 1998. Amplification of target-specific, ligation-dependent circular probe. Gene 211: 277285.

Zhou Y, Huang Q, Gao J, Lu J, Shen X, Fan C. 2010. A dumbbell probe-mediated rolling circle amplification strategy for highly sensitive microRNA detection. Nucleic Acids Res 38: e156. 



A PUBLICATION OF THE RNA SOCIETY

\section{miR-ID: A novel, circularization-based platform for detection of microRNAs}

Pavan Kumar, Brian H. Johnston and Sergei A. Kazakov

RNA 2011 17: 365-380 originally published online December 17, 2010

Access the most recent version at doi:10.1261/rna.2490111

$\begin{array}{ll}\text { References } & \begin{array}{l}\text { This article cites } 72 \text { articles, } 22 \text { of which can be accessed free at: } \\ \text { http://rnajournal.cshlp.org/content/17/2/365.full.html\#ref-list-1 }\end{array}\end{array}$

License

Email Alerting Receive free email alerts when new articles cite this article - sign up in the box at the Service top right corner of the article or click here.

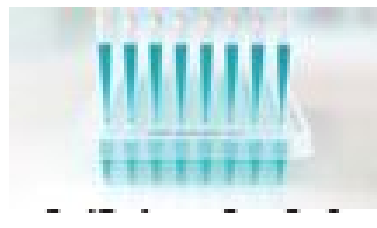

